Portland State University

PDXScholar

6-28-1989

\title{
A Comparison of the Maladaptive Behaviors of Normal, Language Delayed, and Late Talking Toddlers
}

Denise Elaine James

Portland State University

Follow this and additional works at: https://pdxscholar.library.pdx.edu/open_access_etds

Part of the Speech and Hearing Science Commons

Let us know how access to this document benefits you.

\section{Recommended Citation}

James, Denise Elaine, "A Comparison of the Maladaptive Behaviors of Normal, Language Delayed, and Late Talking Toddlers" (1989). Dissertations and Theses. Paper 3894.

https://doi.org/10.15760/etd.5764

This Thesis is brought to you for free and open access. It has been accepted for inclusion in Dissertations and Theses by an authorized administrator of PDXScholar. Please contact us if we can make this document more accessible: pdxscholar@pdx.edu. 
AN ABSTRACT OF THE THESIS OF Denise Elaine James for the Master of Speech Communication: Speech and Hearing Sciences presented June $28,1989$.

Title: A Comparison of the Maladaptive Behaviors of Normal, Language Delayed, and Late Talking Toddlers.

APPROVED BY THE MEMBERS OF THE THESIS COMMITTEE:

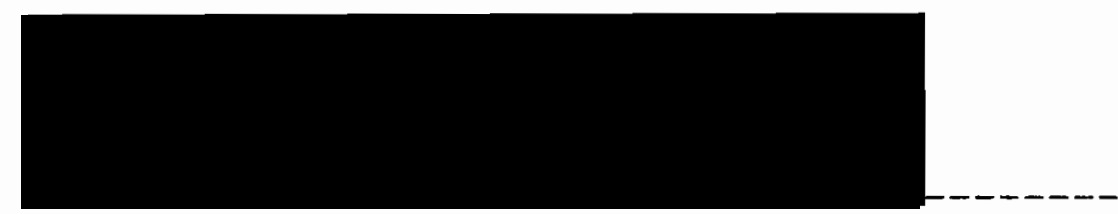

Rhea Paul, Chair

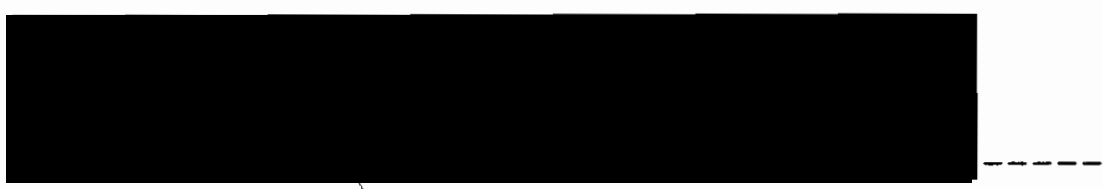

Mary E. Gordon

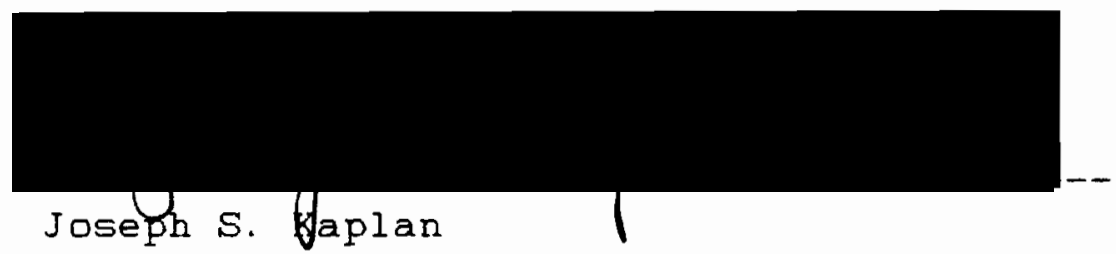

People use language to communicate.their needs and intentions, to express emotions, and to form relationships. It seems likely that a disruption in children's language development would have a negative impact on their sociai development. There is extensive research that shows that school age children with delayed language are "at risk" for Increased maladaptive behaviors (Cantwell and Baker, 1977). 
Whether this is also true for children in the earliest stages of language development is not yet known.

The questions this study sought to answer were: 1) Is there a significant difference in the severity and frequency of maladaptive behaviors seen in language delayed children, children who were "late talkers," or children with normal language? and 2) Is there a signiflcant difference among the three subject groups in terms of which behaviors parents are the most concerned about?

The subjects in this study ranged in age from 18 to 41 months. They included 34 children with delayed language, 12 children who were "late talkers," and 29 children with normal language. The behavior of the subjects was assessed using two parental questionnaires, the Childhood Personality Scale (CPS) (Cohen, 1975), and the Behavior Checoklist for Toddleeㅗ (BCT) (Rescorla, 1984).

The first question was analyzed by calculating the means for each area of behavior assessed and comparing the means among the three subject groups. To determine if there were significant differences among the three subject groups, t-tests were conducted at the .01 level of significance.

The second question was answered by determining what percentage of points, out of the total possible, parents assigned to each area of behavior. The behaviors were then ranked in order according to which areas of behavior parents assigned the highest percentage of points, and to which 
areas of behavior they assigned the lowest percentage of points.

In answering the first question, the CPS showed the language delayed subjects to have significantly more problems than the normal language subjects in the areas of hyperactivity/attention deficit disorder and conduct. The BCT showed the language delayed subjects to have significantly more problems with hyperactivity/attention deficit disorder and relationships. No statistically significant differences were found either between the language delayed subjects and the "late talkers" or between the normal language subjects and the "late talkers."

In answering the second question, the CPS showed no differences among the three subject groups. The BCT found only minor differences among the three subject groups, with the parents of the normal language subjects expressing the most concern about their children's health, and the parents of both the language delayed children and the "late talkers" expressing the most concern about their children's conduct. 
A COMPARISON OF THE MALADAPTIVE BEHAVIORS

OF NORMAL, LANGUAGE DELAYED,

AND LATE TALKING TODDLERS

by

DENISE ELAINE JAMES

A thesis submitted in partial fulfillment of the requirements for the degree of

MASTER OF SCIENCE IN SFEECH COMMUNICATION:

SPEECH AND HEARING SCIENCE

$$
\begin{gathered}
\text { Portland State University } \\
1989
\end{gathered}
$$


TO THE OFFICE OF GRADUATE STUDIES:

The members of the Committee approve the thesis of Denise Elaine James presented June 28, 1989.

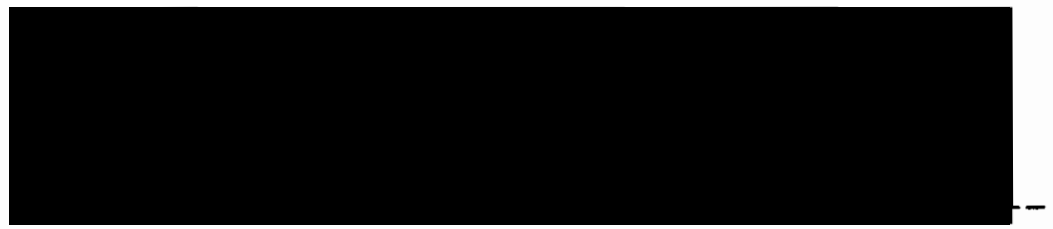

Rhea Paul, Chair

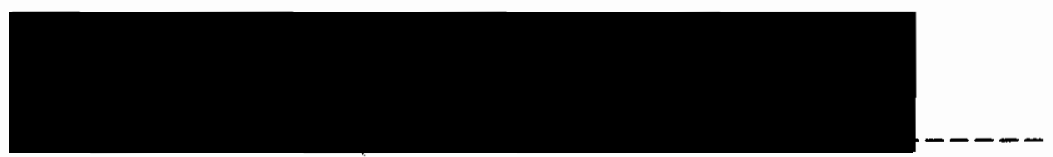

Mary E. Gordon

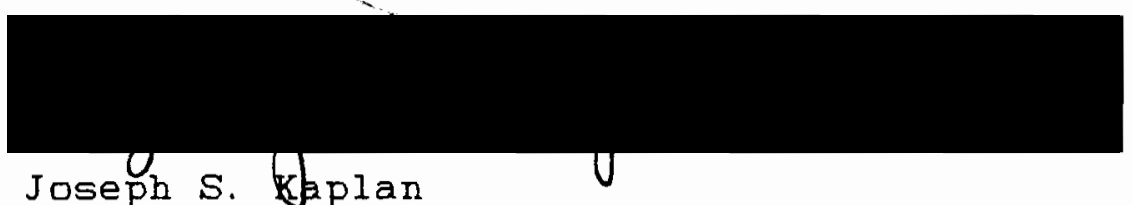

APPROVED:

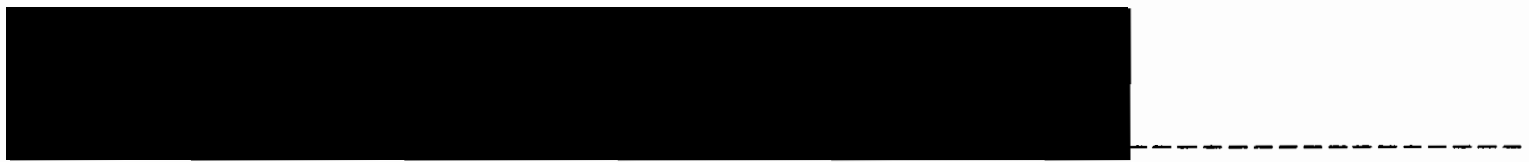

Theodore G. Grove, Chair, Department of Speech Communication

C. William Savery, Interim Vice Provost for Graduate Studies and Research 


\section{ACKNOWLEDGEMENTS}

I would sincerely like to thank Dr. Rhea Paul whose knowledge and research expertise made this study possible. Her patience and support are much appreciated.

I would also like to thank the other members of my thesis committee, Mary Gordon, and Dr. Joseph Kaplan for their valuable contributions. I also owe Mary Gordon a special thank you for her guidance as my academic advisor. Finally, I am very thankful for the love and support of my family. My parents have been a constant source of support as I have completed my education. I am also truly grateful to my husband David James, whose support, encouragement, and endless patience made it possible for me to complete graduate school. 
TABLE OF CONTENTS

Page

ACKNOWLEDGEMENTS

LIST OF TABLES .

LIST OF FIGURES

CHAPTER

I INTRODUCTION AND STATEMENT OF PURPOSE . . . . 1

Introduction . . . . . . . . . . . . . 1

Statement of Purpose . . . . . . . . . . 4

Definition of Terms . . . . . . . . . . . 6

I I REVIEW OF THE LITERATURE . . . . . . . . . . . . . . 8

Behavior Problems of Children with Speech and/or Language Impairments. . . . . . . 8

Studies Differentiating Children with

Speech Disorders from Children with

Language Disorders. . . . . . . . . . 13

Maladaptive Behaviors of Children with

Impaired Language Only . . . . . . . . . 15

Language Delays in Behaviorally Disturbed

Chlidren. . . . . . . . . . . . . 16

Summary . . . . . . . . . . . . . . 19

I I I METHODS . . . . . . . . . . . . . . . . . . . 21

Subject Selection . . . . . . . . . . 21

Instruments . . . . . . . . . . . . 24

Procedures. . . . . . . . . . . . 30

Data Analysis. . . . . . . . . . . 31 
Statistical Analysis. . . . . . . . . 32

Reliablity and Validity . . . . . . . 33

Reliability

Validity

IV RESULTS AND DISCUSSION

Results. . . . . . . . . . . . . . 34

Discussion. . . . . . . . . . . . . 43

V SUMMARY AND IMPLICATIONS

Summary . . . . . . . . . . . . . . 52

Implications. . . . . . . . . . . . . 54

Research Implications

Clinical Implications

SELECTED BIBLIOGRAPHY . . . . . . . . . . . . . . . . . 59 APPENDICES . . . . . . . . . . . . . . . . . . . . . . . . 62

Appendix A . . . . . . . . . . . . . . . 62

Append1x B . . . . . . . . . . . . . . 65

Appendix $\subset$. . . . . . . . . . . . . . 69

Append1x D . . . . . . . . . . . . . . 72 


\section{LIST OF TABLES}

TABLE

PAGE

I Demographic Data for the Subjects on the

Childhood Personality Scale: Means or

Percentages. . . . . . . . . . . . . . .

I Demographic Data for the Subjects on the

Behavior Checklist for Toddlers: Means or

Percentages. . . . . . . . . . . . . . 23

II t-Tests Indicating Differences Between the

Normal (N) and Language Delayed (LD) Subjects

on the Childhood Personality Scale... . .

IV $\quad$-Tests Indicating Differences Between the

Normal (N) and Late Talking (IT) Subjects

on the Childhood Personality Scale. .

$V \quad$ t-Tests Indicating Differences Between the

Language Delayed (LD) and Late Talking (LT)

Subjects on the Childhood Personality Scale.

VI $\quad \underline{t}$-Tests Indicating Differences Between the

Normal (N) and Language Delayed (LD) Subjects

on the Behavior Checklist for Toddlers.. .

VII t-Tests Indicating Differences Between the

Normal (N) and Late Talking (LT) Subjects

on the Behavior Checklist for Toddlers. 
vii

VII t-Tests Indicating Differences Between the Language Delayed (LD) and Late Talking (LT) Subjects on the Behavior Checklist for Toddlers. . . . . . . . . . . . . . . . . . 


\section{LIST OF FIGURES}

FIGURE

PAGE

1. Order in Which Parents Ranked Their Concerns

About the Behaviors Displayed by Their

Children on the Childhood Personality Scale.

2. Order in Which Parents Ranked Their Concerns

About the Behaviors D1splayed by Their

Children on the Behavior Checklist for

Toddlers . . . . . . . . . . . . . . . . . 
CHAPTER I

INTRODUCTION AND STATEMENT OF PURPOSE

\section{INTRODUCT ION}

Much research has been devoted to learning how the behavior of children with language disorders differs from that of their non-language disordered peers. Language is an integral part of being human. It is the single most important factor which separates man from animals. People use language to communicate their needs and intentions, to express emotions, and to form relationships. It seems likely that a disruption in children's language development would have a negative impact on their social development. The research to date shows that a relationship between language development and social development does exist. Several studies report that school-aged language delayed children are at risk for developing behavioral problems, including conduct disorders, attention deficit disorders, difficulty forming relationships, and other maladaptive behaviors such as soiling and crying easily (Cantwell \& Baker, 1977).

Whether or not this is also true for younger children is not yet known.

The speech-language pathologist may question the need to address the problem of maladaptive behaviors in the lan- 
guage delayed child. After all, the role of the speechlanguage pathologist is to remediate speech and language disorders, not behavioral d1sorders. However, there are a number of important reasons why speech-language pathologists must be concerned with behavioral disorders. First, how well children communicate has a major 1 mpact on how they are treated by both adults and other children who come into contact with them. Laughton and Hasenstab (1986) wrote, "An inability to communicate with other children interferes with the establishment of peer relationships. This, in turn, inhibits further social and lingulstic expression" (p. 183). Adults also respond more warmly to children who interact appropriately, and who follow the rules of language use. In turn, the way people respond to children and the input they give them will subsequently affect further language development.

Another important reason for studying the behavior of language disordered children is the possibility that having a language disorder may cause children to develop maladaptive behaviors in order to compensate for their inability to communicate effectively. Laughton \& Hasenstab (1986) hypothesized that maladaptive behaviors such as hyperactivity and withdrawal may be attempts to compensate for poor communcation skills. They hypothesize that the hyperactivity so often seen in language disordered children may be an attempt to describe with actions what they have difficulty 
putting into words. Poor language skills may also result in withdrawal. Withdrawal may occur because language delayed children need more time to process what has been sald, or because they wish to escape from a communicative situation which is too taxing. If maladaptive behaviors do develop as a result of the language delay, teaching children to communicate effectively may be a crucial part of preventing the occurrence of such behaviors.

Third, the clinician must be prepared to deal with problem behaviors if progress is to be made. Children who are hyperactive or inattentive will waste much needed time in counterproductive activities such as squirming in their chairs, gazing out the window, etc. Knowing what maladaptive behaviors to expect from these children is the first step. Once 1t is known what behaviors to expect, the c11nician can begin planning strategies for dealing with any difficulties that may arise because of them. If it is true that children who are language disordered display significantly more maladaptive behaviors, a routine part of any assessment should include assessing the child's behavior. Finally, although this study is not designed to determine a causal relationship between maladaptive behaviors and language delays or disorders, it is hoped that $1 t$ w11l provide some basis from which to formulate some hypotheses. For example, if children under 4 years of age do not display slgnificantly more maladaptive behaviors than their 
"normal" peers, it may be that the maladaptive behaviors develop as a result of the language delay. If maladaptive behaviors are a result of language delay, early language intervention might help to alleviate some of the problems.

In recent years there has been a growing trend toward early intervention for the language delayed child. Until recently, it was a commonly-held belief that young language delayed children, ages 18 to 36 months, are simply "latebloomers" who will in time catch up with their peers. Parents were admonished not to worry and told to delay seeking intervention. Today the current trend is toward early intervention. It is felt that delaying intervention will simply allow language delayed children to lag further behind their peers. If language disorders are identifled early, before maladaptive behaviors emerge, intervention could focus on remediating language without the added difficulty of dealing with a child who is behavior disordered. If on the other hand, maladaptive behaviors do accompany early language delay, intervention may be even more important to curtail problem behaviors as well as remediate the language delay.

STATEMENT OF PURPOSE

The purpose of this study was to determine if language delayed children between the ages of 18 and 41 months, or children who were "late talkers" display significantly more 
maladaptive behaviors than their non-language delayed peers.

The questions this study sought to answer were:

1. Is there a significant difference in the severity and frequency of maladaptive behaviors seen in language delayed children, children who were "late talkers" or children with normal language?"

2. Is there a difference among the subject groups in terms of which behaviors parents are the most concerned with?

The hypothesis of this study is: The maladaptive behaviors of children 18 to 41 months old who have language delays, or who were "late talkers" will be significantly greater in terms of severity and frequency than the maladaptive behaviors of children of the same age who have normal language.

The null hypothesis is: The maladaptive behaviors of children 18 to 41 months old who have language delays, or who were "late talker $\Xi "$ will not differ significantly in terms of severity and frequency from the maladaptive behaviors of children of the same age who have normal language. 


\section{DEF INITION OF TERMS}

The following operational definitions were used for this study:

Conduct - Problems in the area of conduct indicate a child whose behaviors violate the rights of others. Examples of problems with conduct include disturbing other children, defiance, and aggression.

Health - For the purpose of this study, the category of health is simply defined as problems with eating and sleepting.

Hyperactivity/Attention Deficit Disorder (Hyperactivity/ADD) - This category includes the behaviors overactivity, difficulty concentrating and short attention span. The child who displays these characteristics might have more trouble staying on task than other children of the same age. He may become easily frustrated.

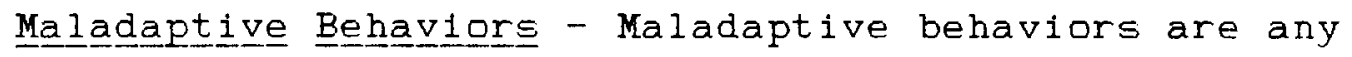
behaviors which are considered negative by parents and others who come into contact with the child. This includes, but is not limited to, the behaviors in this section.

Mood - Problems with mood encompass such areas as anxiety and excessive sadness and includes more worries and fears than normal. The child may seem preoccupied and uninterested in playing.

Relationships - Problems in the area of relationships include shyness, avoidance of others, and poor eye contact. 
The child with this difficulty may have problems forming relationships with his/her siblings and might display problems with attention seeking.

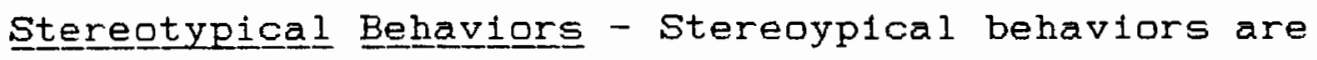
movements or actions that are deliberate, repetitive and serve no useful purpose (American Psychiatric Association, 1980). In this study stereotypical behaviors include head banging, peculiar preoccupations and rocking. 
CHAPTER I I

REVIEW OF THE LITERATURE

There has been a great deal of interest in how children with speech and language disorders develop in terms of their social skills and emotions. It seems likely that if something as integral to being human as language 1 s disrupted, this would have a negative impact on a person in a number of ways. In 1937, Orton stated that communicative disorders of all types would interfere with a person's social and emotional development. This statement has been upheld by a number of different research studies conducted over the years.

\section{BEHAVIOR PROBLEMS OF CHILDREN WITH SPEECH}

\section{AND $/ O R$ IANGUAGE IMPAIRMENTS}

A number of studies conducted over the years have Indicated that children with speech and language disorders are more likely than children without such disorders to display maladaptive behaviors. Cantwell and Baker (1977) conducted an extensive review of the literature and tentatively concluded that there is a higher incidence of psychiatric disorders in children who have speech and language disorders. They also concluded that the types of psychi- 
atric disorders present in this population are not significantly different from those seen in the normal population. These findings were not considered conclusive, however, due to methodological problems such as differences in diagnosing and defining psychiatric disorders, sampling bias and inadequate sampling size, and fallure to consider associative factors such as mental retardation and brain damage.

In an attempt to eliminate some of the methodological problems of the other studies, Cantwell et al. (1979) began a study which included 293 children, ages 1 year, 11 months to 15 years, 11 months from a community speech clinte. Each child was evaluated by a psychiatrist and an interview was conducted with each child's parents and teacher using modified versions of the conners Parent and Teacher Questionnaire (Conners, 1973) and the Rutter Parent and Teacher Questionnaire (Rutter et al., 1970). A diagnosis of a speech and/or language disorder was made by a speechlanguage pathologist.

Cantwell et al. reported their findings for the first 100 subjects in 1979. The results of the psychiatric evaluation indicated that 53 out of the 100 subjects were diagnosed as having at least one psychiatric disorder according to the criteria of the Diagnostic and Statistical Manual of Mental Disorders (DSM-III) (The American Psychiatric Assoctation, 1980). Attention deficit disorder was the most common, occurring in 19 children. This disorder includes a 
developmentally inappropriate short attention span and poor concentration. Oppositional disorder, defined as an opposition to all authority, constant argumentativeness, and an unwillingness to respond to persuasion was the second most common psychlatric disorder. It occurred in 13 of the children. Twelve of the subjects had anxiety disorders; all were shy, 2 were overanxious, and 3 had separation anxiety disorders. Four of the subjects displayed conduct disorders including antisocial behavior which violates the rights of others. One had chronic depression, and 1 had a stereotyped movement disorder. They concluded that children with speech and/or language disorders were "at risk" for psychiatric illness, but a causal relationship was not determined. Mattison, Cantwell and Baker (1980) later reported the findings from administration of the Conners (1972) and Rutter et al. (1970) parent and teacher questionnaires. They found that the items reported most frequently by parents of children with combined speech and language disorders were problems with attentional-motor items (e.g. easily frustrated, excltable, impulsive, restless, short attention span, easily distract-ed, and tantrums), conduct items (e.g., disobeys at home), health items (e.g., nightmares, problems getting to sleep and stomach aches), developmental and language items (e.g., hard to understand), mood items (e.g., angry or 1rritable), and relationship 1tems (e.g., shy, fights with siblings, solitary and afraid of new 
people). Teachers in the study reported much the same data as the parents, and it was determined that both agreed with the findings of the psychiatrist, particularly in the area of attentional-motor items and relationship items. (It must be noted that the study conducted by Mattison, Cantwell and Baker (1980) included 5 mentally retarded children, 4 hearing 1 mpaired children, 2 autistic children, and 1 child from a bilingual background).

In 1982 (a), Baker and Cantwell published further findings on the same subjects. The parents of $40 \%$ of the language delayed children reported that their children's feelings were easily hurt, and $38 \%$ of the parents reported that their children were easily frustrated.

Baker and Cantwell further reported (1982b) that while only $29 \%$ of the children with a pure speech disorder (e.g., articulation disorder, volce disorder, fluency disorder) displayed some type of psychiatric illness (e.g., attention deficit disorders, avoidance disorders, oppositional disorders, separation anxiety disorders, adjustment disorders or affective disorders), $45 \%$ of the children with combined speech and language disorders, and a total of $95 \%$ of the children with a language disorder (e.g., expressive, receptive, or processing disorder no less than 6 months below age level) were diagnosed as psychiatrically ill.

Fifty-three percent of the children in the 1979 Cantwell et al. study were found to have "diagnosable 
psychiatric disorders according to DSM-III criterla" ( $p$. 499, Baker and Cantwell, 1987). In 1987 they published their findings on these children. The majority of differences and those which were most significant between the two groups were in the area of language development. They found that "The psychiatrically ill children showed significantly more disorders involving language, whereas the psychiatrically well children tended to have fewer disorders involving language and more disorders involving pure speech" (p. 507). Also, their expressive and receptive language deficits were more severe than those of the psychiatrically well children. The only developmental milestones which distinguished the 11 children from the well children were the age at which the first word and the first sentence were spoken. The psychiatrically ill children were significantly delayed in both these areas. Cantwell and Baker (1987) found that speech and language are the factors "most significantly associated with psychiatric illness" ( $p .508$ ). They point out that this may mean that "speech and language factors may play a more direct role in the development of psychiatric disorders than has been previously hypothesized" (p. 508).

There have been other studies which support the finding that an association exists between speech and language disorders and behavioral disorders. Botelho (1986) cited the research of Beckey (1942) who observed children and reviewed teachers' reports to determine what factors were 
related to delayed speech development (delayed speech development was not defined) and concluded that these children did not want attention, played alone, and cried easily. Botelho (1986) further reports that unlike Cantwell and Baker (1980), Beckey did not consider temper tantrums and thumb sucking to be frequently occurring behaviors in the delayed speech children.

\section{STUDIES DIFFERENT IATING CHILDREN WITH SPEECH DISORDERS FROM CHILDRN WITH LANGUAGE DISORDERS}

Studies have indicated that the type and severity of maladaptive behaviors observed in children are related to the type and severity of their communication deficit.

Baker, Cantwell and Mattison (1980) compared the behavior of 46 children with "pure" speech disorders to that of 53 children with combined speech and language disorders and found that significant differences did exist. Children with combined speech and language disorders were rated signiflcantly worse in terms of hyperactivity syndrome (e.g., excessive motor activity, attentional deficit, etc.), conduct disorders, establishing relationships and develop developmental phenomena (e.g., wetting bed/pants, crying easily, etc.).

Cantwell and Baker (1982a) concluded from their research that children with language disorders were much more likely to be psychiatrically 111 than the children with pure speech disarders. Eighty-seven percent of the psychi- 
atrically 111 children had language disorders while only $36 \%$ of the psychiatrically well children had language disorders.

A study by Botelho (1986) supports these findings.

Included in her study were 19 subjects between the ages of 5 and 11 years with speech and/or language impairments matched for age and sex with 19 subjects who had normal speech and language as determined by school records and a speechlanguage pathologist. Each group contained 14 boys and 5 girls. Behavior was evaluated using the Child Behavior Checklists (Achenbach \& Edelbrock, 1983). Both parent and teacher questionnaires were used.

In comparing the speech and/or language impaired subjects to the normal subjects, Botelho (1986) found no significant differences. Upon dividing the boys into three groups, however, speech and language 1mpaired, language impaired and speech impaired, she found significantly more maladaptive behaviors in both the speech and language impaired, and language impaired boys as compared to the speech impaired and normal boys. As with the boys, the girls displayed no significant differences between the speech and/or language impaired girls and the normal girls. They were not further subdivided into three groups because of the small number of female subjects.

The types of problems teachers identifled more frequently in the speech and language, and language impaired boys included significantly lower school performance, inat- 
tentiveness, agressiveness, and more difficulty learning.

These same differences were not reported by the parents, but Botelho (1986) speculated that the problems seen may be due to the more taxing language demands placed on children in school.

\section{MALADAPTIVE BEHAVIORS OF CHILDREN WITH}

\section{IMPAIRED LANGUAGE ONLY}

Researchers have long suspected that language delays or disorders are related to behavioral and emotional problems. In 1959, Ingram remarked upon the large number of behaviorally disturbed children being seen by speechlanguage pathologists. Weiner (1968) also reported a high number of behaviorally disturbed children being seen by speech-language pathologists. The research which has been done to date supports these findings.

Stevenson and Richman (1978) conducted an epidemiological study of the language and behavior of 3 -year old children. They took a random sample of 705 children. Using a test of expressive and receptive language, they found that $24(3.1 \%)$ of the children had a language delay. They used a Behavior Screening Questionnaire to identify behavior problems and found that 101 (14.3\%) of the children in the sample displayed behavior problems. Stevenson and Richman (1978) found that of the children with language delays, 59. $1 \%$ had behavior problems. Th1s is highly significant 
when one considers that only $14.3 \%$ of the sample population displayed any behavioral problems. Also significant was the fact that $12.9 \%$ of the children identified as having behavfor problems also were language delayed compared to $3.1 \%$ of the sample population who were language delayed.

In comparing the types of behavior problems seen in language delayed and non-language delayed children, Stevenson and Richman (1978) found few differences except that the behavior problems of the language delayed children were more severe. The types of problems they observed were most frequently in social relationships (e.g., dependency, relationships with siblings, relationships with peers). Also reported were problems with parental control, unhappy moods, poor appetite, overactivity, and difficulty concentrating.

\section{LANGUAGE DELAYS IN BEHAVIORALLY DISTURBED CHILDREN}

Other researchers have studied the language delays of children who display maladaptive behaviors. Some studies Include children in child guidance centers (Chess \& Rosenberg, 1974; Wyl1e, Franchak, \& McW1lliams, 1965), and others have studied behaviorally, emotionally disturbed children attending public schools (Camarata, Hughes, \& Ruhl, 1988).

Wylie, Franchak, and MoWilliams (1965) found that $15 \%$ of a total of 292 children in a community child guidance 
clinic diplayed what they referred to as "defective speech," including $27 \%$ who had articulation problems, $24 \%$ with delayed speech, $20 \%$ who stuttered, and $29 \%$ who had combined disorders. Five maladaptive behaviors were seen in the children with "defective speech" significantly more often than in the children with normal speech: Solling, thumbsucking, wetting, hyperactivity and involuntary movements. Only two of these behaviors, solling and thumbsucking, were found to occur at a statistically significant level. It was noted by Wylie et al. that the fact that the children with Impalred speech were significantly younger may have influenced their findings. The children with impalred speech ranged in age from 2 to 16 years with a mean age of 8 and a mode of 6 . The children with normal speech included children aged 3 to 17 years, w1th a mean age of 10 and a mode of 9.

A study conducted by Chess and Rosenberg (1974) also looked at children in a child guldance center. They found that parents of $64 \%$ of the speech and language disordered children reported behavioral problems, including tantrums, disruptive behavior, difficulties in peer relationships, disclpline problems, enuresis, separation anxlety, withdrawn behavior, hypochondriasm, and extreme sullenness. Hyperact1vity was reported as a problem in $19 \%$ of the speech and language disordered subjects. 
An interesting outcome in both the Wylie et al. (1965) study and the Chess and Rosenberg (1974) study is the Incldence of chlldren with articulation disorders versus children with language disorders. Normaliy, articulation comprises around $54 \%$ of all speech and 1 anguage disorders (Spilka \& Steer, 1951; Van R1per, 1954). Only 27\% of the children in the child guidance centers studied by the researchers had articulation disorders. This may be an Indicator that children with articulation disorders are less likely than children. with language disorders to develop maladaptive behaviors.

Camarata, Hughes, and Ruhl (1988) conducted a study to determine if mild to moderately behavior disordered children have more significant language delays than children whose behavior is normal. Included in the study were 38 children identified as mild to moderately behavior disordered who were "enrolled at least part-time within special education classrooms in regular elementary schools" (p. 193). The subjects ranged in age from 8 years, 9 months to 12 years, 11 months. The Test of Language Development-Intermediate (TOLI--I) (Hammill \& Newcomer, 1982) was used to assess the subjects' language development. It was administered with the following results: 27 (71\%) of the subjects' standard scores fell two or more standard deviations below the mean of the normative data reported for the test on one or more subtests. Of the 11 remaining subjects, all but 1 scored 
more than one standard deviation below the mean on one or more subtests. However, the intelligence quotients of the subjects in this study ranged from 67 to 126 . Since the normative data on the TOLD--I is based on children with intelligence quotients in the normal range, Camarata and Hughes also reported separately for those subjects in their study who had normal IQ's. Of the remaining 21 subjects with normal IQ's, 20 received standard scores one or more standard deviations below the mean of the normative sample on one or more subtest $s$.

\section{SUMMARY}

In surveying the Iiterature, it is apparent that children with speech and/or language disorders are "at risk" for developing maladaptive behaviors. Several studies have shown a higher prevalence of behavior disorders in these populations (Cantwell \& Baker, 1977). It has also been found that children with elther combined speech and language disorders or language disorders display a higher incidence of maladaptive behaviors than do children who have only speech disorders. Cantwell and Baker (1982b) found that only $29 \%$ of children with pure speech disorders displayed maladaptive behaviors while $45 \%$ of the children with speech and language disorders and $95 \%$ of the children who had only a language 19 disorder displayed some type of psychiatric iliness. 
However, while much is known about problem behaviors of language delayed or disordered children aged 3 and up, no research has focused strictiy on children aged 3 and under. Cantwell et al. (1979) included subjects in their study who were as young as 1 year, 11 months old, but the study also included subjects as old as 15 years, 11 months. Wylie et al. (1965) studied children as young as 2 years old, but the mean age of the subjects was 8 , and the mode 6 .

The only study to date which has specifically focused on preschool children is that of Stevenson and Richman (1978) who did an epidemlological study of 3 year old children. They found that much like older children, 3 year old children who have language delays are significantly more likely than non-language delayed children to display maladaptive behaviors. However, it cannot be assumed that even younger children will follow the same pattern.

The importance of a study focusing on children in the earliest stages of language development must not be overlooked. It may be of real benefit in helping to solve the problem of the relationship between language delays or disorders and maladaptive behaviors. If nothing else, $1 t$ will a1d speech-language pathologists in deciding what areas to assess in the very young child. 


\section{CHAPTER I I I}

\section{METHODS}

\section{SUBJECT SELECT ION}

Three groups of subjects were used for this study: Language delayed, "late talkers," and children with normal language. The subjects were recruited for the study using media advertisements and referrals from local pediatric clinics. The language delayed (ID) group consisted of 34 children between the ages of 19 and 41 months. The determination of a language delay was made using the criteria outIined by Rescorla (1984). Children were considered language delayed if between the ages of 18 and 23 months they used less than 10 words, or if between 24 and 30 months of age their expressive vocabulary was less than 50 words and/or they used no two-word combinations. The second group, the "late talkers," consisted of 12 subjects between the ages of 19 and 41 months. The "late talkers" were those children initially classified as language delayed because their expressive vocabularies were less than 10 words at 18 to 23 months. However, these children's vocabularies "caught up," exceeding 50 words by 24 months of age. The third group, the normal language subjects, consisted of 33 children matched to the other two groups by age, sex ratio, and 
socioeconomic status (SES). They were placed in the normal language group because their language exceeded the criteria outilned for language delay.

SES was determined using a four-factor scale developed by Myers and Bean (1968). SES scores on this scale range from 1 to 5 with one being the highest.

The subject data is reported on two separate tables as two behavioral questionnaires, (a) the Childhood Personality Scalle (CPS) (Cohen, 1975), and (b) the Behavior Chenecklist for Todㅁlers (BCT) (Rescorla, 1984) were used in this study. The CPS was administered, on the average, 5 to 7 months later than the BCI. Therefore the mean age of the subjects is slightly higher on the CPS than it is on the BCT (See Tables I and II). Also, the number of subjects for the two behavioral questionnaires vary slightly as both questionnaires were not filled out by all parente.

\section{TABLE I}

DEMOGRAPHIC DATA FOR THE SUBJECTS ON THE CHILDHOOD PERSONALITY SCALE: MEANS OR PERCENTAGE.

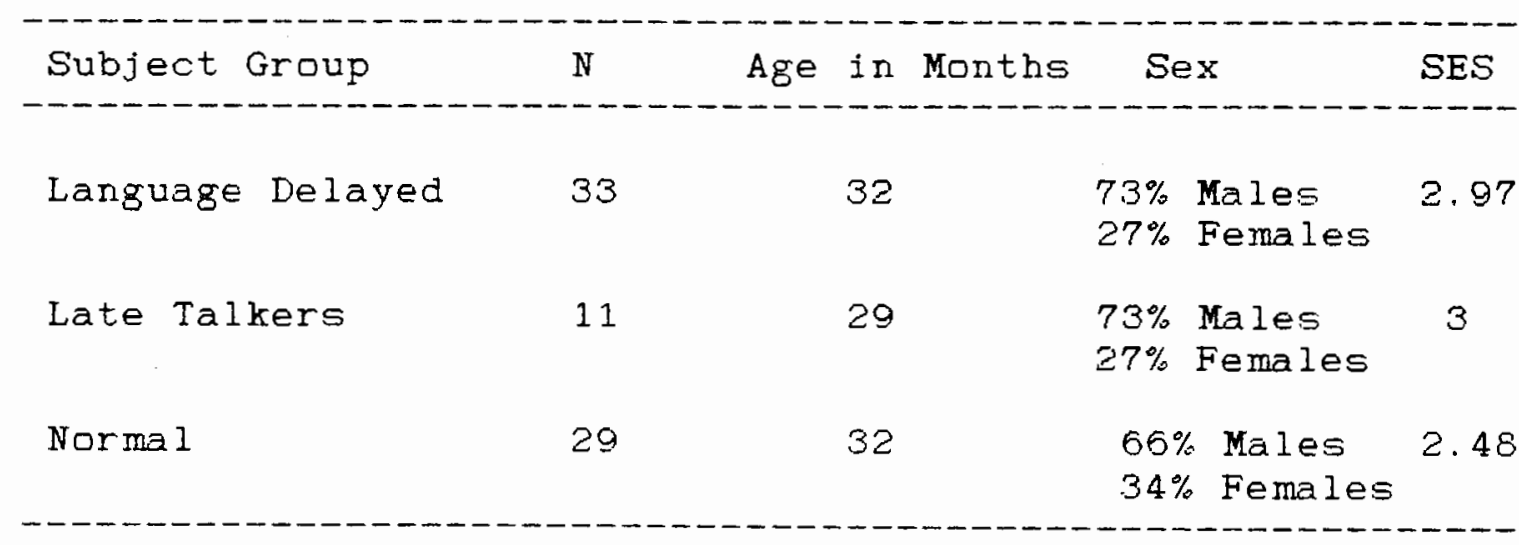


TABLE I I

DEMOGRAPHIC DATA FOR THE SUBJECTS ON THE BEHAVIOR CHECKLIST FOR TODDLERS: MEANS OR FERCENTAGE.

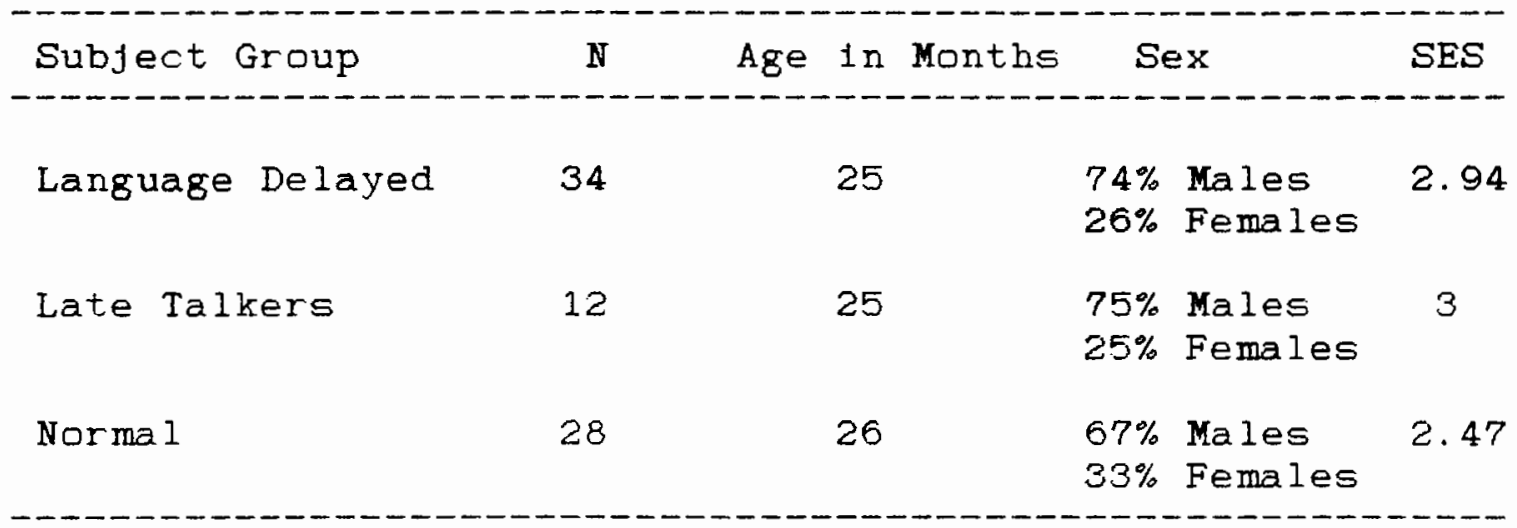

A determination of the child's level of expressive vocabulary was made by having the parents fill cut the Language Development Survey (LDS) (Rescorla, in press) (Appendix A). The LDS lists 350 common early words and parents are asked to circle the words their child says. The LDS has been shown by Rescorla to have excellent reliability, validity, sensitivity (i.e., the abllity to correctly identify delayed children), and specificity (i.e., the ability to identify normal children as normal).

In order to be eligible to participate in the study, the children whose parents filled out the IDS had to meet a number of requirements. First, they had to have normal hearing as measured by passing a hearing screening at $25 \mathrm{~dB}$ In a sound field. Second, they had to have normal intelligence as determined by a score of 80 or above on the Mental Development Index of The Bayley Scales of Infant Development 
(Bayley, 1969). Finally, subjects included in the study could show no signs of the disorders of autism, craniofacial or neuromotor dysfunction, as determined by the observation of a speech-language pathologist. All children who participated in this study passed the above screening measures.

\section{INSTRUMENTS}

The behavior of the subjects was assessed using two questionnalres filled out by the parents: (a) the CFS and, (b) the BCT. Each questionnaire requires the parent to read a word or sentence and assign a number designating the degree to which it describes their child.

The decision to use both questionnaires in this study was based upon several factors. First, both questionnaires were avaliable at the time the data were collected. Second, the two questionnaires provide somewhat different information. The CPS requires the parents to judge how frequently a behavior occurs in their child. It also requires them to provide responses to very specific behavioral items such as "Turns his head away or looks down in an uncomfortable way wher people pay attention to him." It was designed to assess psychiatric disorders in children from 18 months to 12 years of age. This makes 1 t a useful tool if at later date a follow-up study is conducted using these subjects. The BCT was designed specifically to assess the behavior of toddlers and requires the parent to make a more 
general appraisal of their child's behavior. Rather than requiring parents to judge the frequency of certain behavlors their child displays, they are required to make a judgement of whether a behavior such as "shyness," or "moods" is "no problem," "some problem," or a "major problem". It may be that the items on the BCT are somewhat more relevant for toddlers. Also, it includes information on two areas of behavior that are not covered on the CPS, namely health and stereotypical behaviors. These are 1 tems that were covered in other studies and it was felt by this researcher that this information was important.

The CFS (Appendix B) has three separate sections, two of which were used for this study. The first section allows the individual to assign a score from 0 to 6 , or how often each behavior is observed in the child ( $1 . \mathrm{e}, 0=$ Never, $1=$ Almost Never, $2=$ Seldom, $3=$ Half the Time, $4=$ Frequently, 5 = Almost Always, 6 = Always). Eighteen items out of a total of 20 were used from the first section. The 2 items which were not used assessed language rather than behavior. Most statements in the first section refer to behaviors which are negative or maladaptive, but some refer to behaviors which are positive or adaptive. In order to use both the negative and positive statements, the scoring was reversed for the positive behaviors (1.e., a score of 0 became a score of 6 ; a ecore of 1, 5; a score of 2, 4; a score of 3 remained 3 ; a score of 4 became 2 ; a score of 5 , 
1 ; and a score of 6,0 .

The second section of the CPS has a statement in which the person is asked to assign a number indicating how closely that statement describes the child (e.g., $0=$ Not At All, 1 = Just a Iittle, 2 = Pretty Much, 3 = Very Much). All 12 items from this section were used in the study.

The third section of the CPS was not used for the purpose of this study as it asked parents to make more of a general rating of their child's skills and did not cover specific behaviors.

The BCT (Appendix B) has only one section with a number scale from 0 to 2 (i.e., $0=$ No Problem, $1=$ Some Problem, 2 = Major Problem). The BCT has a total of 26 items. Only 25 of the 1tems were used as one, "stuttering/ stammering" assesses speech rather than behavior.

In order to facilitate comparisons across the two scales, as well as comparisons within the research literature, the items on the instruments were grouped into categories; on the CPS these categories include hyperactivity/ $A D D$, immature relationships, conduct, and mood; on the BCT these categories include hyperactivity/ADD, immature relationships, conduct, mood, health and stereotypical behaviors. 
On the CPS, Section 1, hyperactivity/ADD included the following items:

1. 'Loses interest in what he has started doing. Goes from one thing to another.'

2. 'Jumps, runs and is on the move. Can't seem to be st111 for long.

3. 'Persists in trying to do something, even if he has some small problems along the way.' *

4. Quickly shows his anger and frustration if he can't get something done that he's working on.

5. 'Gives long attention to objects, toys or books that interest him.'*

6. 'Can get away from you quick as a flash when he wants to.'

7. 'Can pay attention to a long time to something. '*

8. 'Active, impossible to keep up with him.'

Hyperactivity on Section 2 of the CPS included:

9. 'Restless (overactive).'

10. 'Excitable, impulsive,'

11. 'Fails to finish things he starts,'

12. 'Fidgeting,'

13. 'Inattentive, distractible'

14. Demands must be met immediatly; easily frustrated.'

A Hyperactivity score for the CPS was calculated by combining the scores for Sections 1 and 2 . 
On the BCT hyperactivity/ADD included:

1. 'Overactivity'

2. 'Concentration'

3. 'Is impulsive.'

The child's ability to form relationships and his social skills were also assessed. On Section 1 of the CPS this category included:

1. Turns his head away or looks down in an uncomfortable way when people pay attention to him.'

2. 'Shies away from getting attention.'

3. 'Tends to be resistant and unfriendly.'

4. Would rather be left alone if you try to play with him or talk to him.'

5. 'Smiles to a friendly person'*

Section 2 of the CPS did not include any relationship items.

On the BCT problems with relationships included:

1. 'Attention seeking'

2. 'Shyness'

3. 'Relationships with brothers/ sisters.'

4. 'Overly dependent'

5. Poor eye contact.' 
The third category of behavior assessed was conduct. On the CPS this included only two items in section 2:

1. 'Disturbs other children.'

2. 'Temper outbursts.'

On the BCT conduct included these characteristics:

1. 'Difficult to manage.'

2. 'Aggression.'

3. 'Defiant.'

Mood was assessed using both sections of the CPS. On Section 1 problems with mood included:

1. 'Lies down, rests his head, or falls asleep 1nstead of playing.'

2. 'Sits without doing anything unless another person tries hard to get him interested.'

3. Seems to have little zest for normal actlvities. Acts tired.'

4. 'Talks and acts happily and with excitement about things that interest him.' *

On Section 2 of the CFE mood included:

1. 'Cries'

2. 'Mood charges quickly.'

3. 'Temper outbursts.'

4. 'Anxious.'

5. 'Overly sad.' 
On the BCT mood included:

1. 'Moods.'

2. 'Worries.'

3. 'Fears.'

4. "Withdrawn, "spacey."'

5. 'Cries or laughs too easily.'

Health was assessed only on the BCT as the CPS has no 1tems which fit in this category. It included only problems with:

1. 'Eat1ng'

2. 'Sleeping'

Stereotypical behaviors were also assessed only on the BCT. This category included:

1. 'Echoes speech.'

2. 'Repetitive habits (flapping, twirling).'

3. 'Tics.'

4. 'Pecullar preoccupations.'

5. 'Rocks back and forth.'

6. 'Bangs head.'

*Scoring will be reversed

\section{PROCEDURES}

The behavioral questionnaires were filled out by either one or both parents together. The parents were given the questionaire with the instructions to fill it out as they felt it best described their child. The CPS was given to 
parents to fill out at home and they returned it by mail. The BCT was filled out by parents while they waited for language testing to be completed on their child.

\section{DATA ANALYSIS}

In order to compare the language delayed subjects, the "late talkers" and the normal language group, each child was assigned a score for each of the behavioral categories based upon the parent's rating. The scores were tallied using the coding sheets in Appendix C. The subject's scores are reported in Appendix $D$. The total score possible varied among the different behavioral categories. On the CFS the total possible score for hyperactivity/ADD was 66; the total possible for relationships was 30 ; the total possible for mood was 39 ; and the total possible for conduct was 6 . On the BCT the total possible score for hyperactivity/ADD was 6; the total posstble for relationships was 10; the total possible for mood was 10 ; the total possible for conduct was 8; the total posslble for stereotypical behaviors was 12 ; and the total possible for health was 4.

After determining the mean score for each area of behavior for each of the three subject groups, the means were then compared to determine if a significant difference existed among the LD, "late talkers," and normal language The two behavioral questionnaires, the CPS and the BCT were analyzed separately. 


\section{STATISTICAL ANALYSIS}

The first question posed by this study was "Is there a significant difference in the severity and frequency of maladaptive behaviors displayed among the three subject groups?" To answer this question, t-tests were conducted to determine if there were any differences between either the normal langauge subjects and the LD subjects; the normal language subjects and the "late talkers"; or the LD subjects and the "late talkers." The t-tests were conducted at the .01 level of significance. A.01 level of significance was chosen as 30 t-tests were conducted and 1 t was felt that using a lower level of significance would result in too high a percentage of Type I errors. The second question this study sought to answer was "Is there any difference among the three subject groups in terms of what types of behaviors: parents are the most concerned about?" This question was answered by determining which areas of behavior parents assigned the highest percentage of total points possible to and to which area of behavior they assigned the lowest percentage of points possible. The areas of behavior were then ranked in order from highest to lowest percentage of points asહ1gned. 


\section{Re 1 ia $\underline{b} 1$ I1 1 ty}

As a check on the researcher's scoring, $10 \%$ of the tests were rescored by a person who was trained as to how the tests were scored. The average percentage of agreement was $98 \%$.

\section{VaIㅣ르느}

To check the validity of the categorization of the items on the two questionnaires into the factors of hyperactivity/ADD, relationships, mood, conduct, health and stereotypical behaviors, two other people categorized the items. The fudges had no special background, but were trained as to what the behavioral terms in the study meant. The judges agreement with this author was, on the average, $90 \%$ on the BCT and $85 \%$ on the CPS. 


\section{CHAPTER IV \\ RESULTS AND DISCUSSION}

RESULTS

The purpose of this study was to determine if differences exist in the severity, frequency, and type of maladaptive behaviors seen amorg language delayed children, children who were "late talkers," and normal language children aged 18 to 41 months as reported by parents. Two parent questionnatres were used, The Chilldhood Per (CFS) (Cohen, 1975) and The Eehavinior Checklist fon for Toddlers (BCT) (Rescorla, 1984).

The first question addressed was whether or not significant differences exist in the severity and frequency of maladaptive behaviors reported for LD children, children who were "late talkers," and normal language children. To answer this question, the means were compared for each behavioral category assessed on the two questionnatres for each of the three subject groups using t-tests. The differences among the subject groups are reported in Tables II , IV, and $V$ for the CPS and in Tables VI, VII, and VIII for the BCT. Differences between the subject groups were considered significant at the. 01 level. 
On the CPS differences were found between the LD subjects and the normal subjects for both hyperactivity/ADD and conduct with the LD subjects displaying signiflcantly more maladaptive behaviors in both these areas (See Table III).

TABLE I I I

t-TESTS INDICATING DIFFERENCES BETWEEN THE NORMAL (N) AND LANGUAGE DELAYED (LD) SUBJECTS ON THE

CHILDHOOD PERSONALITY SCALE.

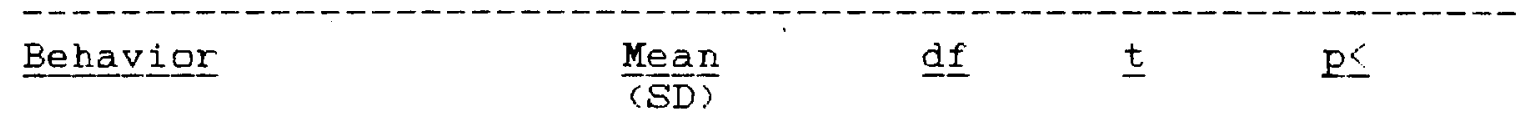

Hyperactivity $A D D$

Relationships

Mood

$$
\begin{gathered}
N-\begin{array}{c}
5.07 \\
(3.16)
\end{array} \\
L D-\begin{array}{c}
7.74 \\
(5.30)
\end{array}
\end{gathered}
$$

$$
L D-30.26
$$$$
\text { (9.23) }
$$

$$
\begin{array}{r}
N-6.14 \\
(4.71) \\
L D-8.70 \\
(5.88)
\end{array}
$$

$61-2.911$

$<.010 *$

$61-1.900$

.118

$55 \quad-2.477 \quad .034$

Conduct

$$
\begin{array}{r}
N-\begin{array}{r}
1.36 \\
(.95)
\end{array} \\
L D-\begin{array}{l}
2.18 \\
(1.38)
\end{array}
\end{array}
$$

$59-2.748<.010 *$

* Significant 
The CPS showed no signiflcant differences between the normal subjects and the "late talkers" or between the delayed subjects and "late talkers" (See Tables IV and V).

TABLE IV

$\underline{t}$-TESTS INDICATING DIFFERENCES BETWEEN THE

NORMAL (N) AND LATE TALKING (LT) SUBJECTS

ON THE CHILDHOOD PERSONALITY SCALE.

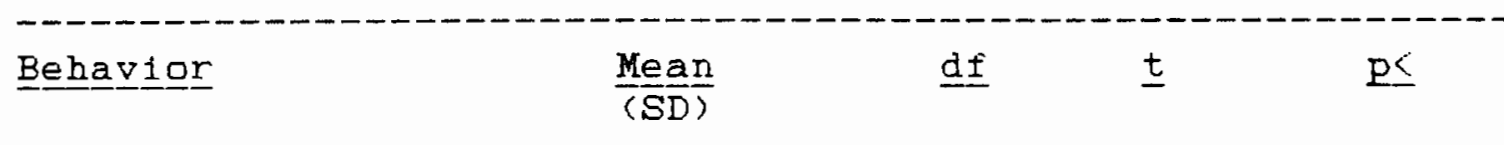

Hyperactivity/ADD N -23.40

(9. 29)

$$
\text { LT - } \begin{aligned}
& 31.09 \\
& (7.50)
\end{aligned}
$$$$
24 \quad-2.705 \quad .024
$$

Relationships

$$
\begin{array}{r}
N-6.14 \\
(4.71) \\
L T-7.73 \\
(4.40)
\end{array}
$$$$
21-1.000 \quad .999
$$

Mood

$$
\begin{aligned}
& N-5.07 \\
& \text { (3.16) } \\
& \text { LT }-\frac{9.50}{(5.22)}
\end{aligned}
$$$$
13-2.638 \quad .040
$$

Conduct

$$
\begin{aligned}
& N-1.36 \\
& \text { (.95) } \\
& L T-2.50 \\
& \text { (1.32) }
\end{aligned}
$$$$
15-2.608 \quad .038
$$ 
TABLE V

t-TESTS INDICATING DIFFERENCES BETWEEN THE LANGUAGE DELAYED (LD) AND LATE TALKING (LT) SUBJECTS ON THE CHILDHOOD PERSONALITY SCALE.

Hyperactivity/ADD LD - 30.26

(9.23)

$$
\begin{array}{r}
I T-31.09 \\
(7.50)
\end{array}
$$

$$
23-.300 \quad .999
$$

Relationships

$$
\begin{aligned}
& L D-8.70 \\
& \text { (5. 88) } \\
& \text { LT }-7.73 \\
& \text { (5. 40) }
\end{aligned}
$$

$25 \quad .579 \quad .999$

Mood

$$
\begin{array}{r}
L D-\begin{array}{r}
7.74 \\
(5.30)
\end{array} \\
L T-\begin{array}{r}
9.50 \\
(5.22)
\end{array}
\end{array}
$$

$$
17 .-964 \quad .999
$$

Conduct

$$
\begin{gathered}
\text { LD }-\begin{array}{c}
2.18 \\
(1.38)
\end{array} \\
\text { LT }-\begin{array}{c}
2.50 \\
(1.32)
\end{array}
\end{gathered}
$$

$$
19-.683 \quad .999
$$

The BCT showed the LD subjects to have significantly higher scores than the normal subjects in the areas of hyperactivity/ADD and relationships. No significant differences were found between the normal and LD subjects in the areas of mood, conduct, health or stereotypical behaviors (See Table VI). 
TABLE VI

t-TESTS INDICATING DIFFERENCES BETWEEN THE NORMAL (N)

AND LANGUAGE DELAYED (LD) SUBJECTS ON THE BEHAVIOR CHECKLIST FOR TODDLERS.

\section{Behavior}

Hyperactivity/ ADD

Relationships

$$
\begin{array}{r}
N-\begin{array}{r}
.62 \\
(.81)
\end{array} \\
L D-\begin{array}{c}
1.62 \\
(1.60)
\end{array}
\end{array}
$$

Mod

$$
\begin{gathered}
N-\begin{array}{c}
.67 \\
(.84)
\end{array} \\
L D-\begin{array}{l}
1.18 \\
(1.42)
\end{array}
\end{gathered}
$$

56

$$
-1.765
$$$$
.158
$$

$-3.214$

$<.010 *$

Conduct

$$
\begin{gathered}
N-\begin{array}{c}
1.17 \\
(1.21)
\end{array} \\
L D-\begin{array}{l}
2.08 \\
(2.38)
\end{array}
\end{gathered}
$$

62

$-2.639$

.020

Health

$$
\begin{array}{r}
N-\quad .63 \\
(.75) \\
L D-\quad .74 \\
(.75)
\end{array}
$$

58

$-.479$

.999

Stereotyplcal

Behaviors

$$
\begin{array}{r}
N-.33 \\
(.80) \\
L D-.53
\end{array}
$$$$
62
$$$$
-1.007
$$$$
.638
$$ 
No significant differences were found between the normal subjects and "late talkers" or between the LD subjects and the "late talkers" on the BCT (Tables VII and V I I I ),

The second question addressed in this study was whether or not differences exist between the subject groups in terms of which behaviors parents are the most concerned with. In other words, for each subject group, to what behaviors did parents assign the highest scores, and to what areas of behavior did they assign lower scores? Since the categories of maladaptive behaviors do not contain equal numbers of points possible on either of the two questionnaires, a rank ordering was determined by dividing the total points possible on a particular category of behavior by the mean recelved by the subject group. On the CFS, no differences were found between the types of concerns displayed by the parents of each subject group. That 1s, parents of LD children, normal language children and "late talkers" all assigned the highest percentage of possible points to the category hyperactivity/ADD. The parents ranked concern about their child's conduct, second, immature relationships, third, and mood last. The results are displayed in Figure 1.

Some differences did occur in the parents concerns as outlined by the BCT. Parents of both the late talkers" and the ID subjects were most concerned with their child's 


\section{TABLE VII}

\section{t-TESTS INDICAT ING DIFFERENCES BETWEEN THE NORMAL (N) AND LATE TALKING (LT) SUBJECTS ON THE BEHAVIOR CHECKLIST FOR TODDLERS.}

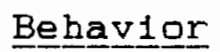

Hyperactivity/ $A D D$

Relationships

Mood

Conduct

$$
\begin{aligned}
& \text { N }-.67 \\
& \text { (.84) } \\
& \text { LT - . .58 } \\
& \text { (1. 17) }
\end{aligned}
$$

26 $.225 \quad .999$

$\begin{array}{lll}18 & -1.658 \quad .222\end{array}$
$17 \quad-2.158 \quad .086$

$$
N-1.17
$$$$
\text { (1. 21) }
$$

$$
\begin{aligned}
& \text { LT }-2.08 \\
& \text { (2.38) }
\end{aligned}
$$

$14 \quad-1.502 \quad .304$

Health

$$
\begin{aligned}
& \mathrm{N}-.63 \\
& \text { (.93) } \\
& L T-\begin{array}{l}
.75 \\
(.75)
\end{array}
\end{aligned}
$$$$
\begin{array}{llll}
27 & -.423 & .999
\end{array}
$$$$
\begin{array}{lll}
41 & .903 & .999
\end{array}
$$ 
TABLE VII I

t-TESTS INDICATING DIFFERENCES BETWEEN THE LANGUAGE DELAYED (LD) AND LATE TALKING (LT) SUBJECTS ON THE BEHAVIOR CHECKLIST FOR TODDLERS.

\section{Behavion}

Hyperactivity/

ADD

Relationships

Mood

Conduct

Health

Stereotypical

Behaviors

\section{Mean}

$$
\begin{array}{r}
L D-\begin{array}{c}
1.18 \\
(1.47)
\end{array} \\
L T-\begin{array}{r}
.92 \\
(.90)
\end{array}
\end{array}
$$

$$
.718 \quad .999
$$

\section{$\mathrm{p} \leq$}

$\begin{array}{lll}\mathrm{d} f & \underline{\mathrm{t}} & \mathrm{p} \leq \\ 35 & .718 & .999\end{array}$

$33 \quad-1.115 \quad .546$

$$
\begin{array}{r}
\mathrm{LD}-\begin{array}{c}
1.62 \\
(1.60)
\end{array} \\
\mathrm{LT}-\begin{array}{c}
1.17 \\
(1.03)
\end{array}
\end{array}
$$

$$
L D-\begin{aligned}
& 1.18 \\
& (1.42)
\end{aligned}
$$

$$
\text { LT }-\frac{.58}{(1.17)}
$$

$\begin{array}{lll}26 & 1.427 & .324\end{array}$

$$
\begin{array}{r}
\mathrm{LD}-\begin{array}{c}
2.10 \\
(1.62)
\end{array} \\
\mathrm{LT}-\begin{array}{c}
2.08 \\
(2.38)
\end{array}
\end{array}
$$

$14 \quad-.198 \quad .999$

$$
\begin{aligned}
& L D-\quad .74 \\
& \text { (.75) }
\end{aligned}
$$

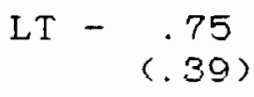
$-.058 \quad .999$

$$
\begin{array}{r}
L D-.53 \\
(.75) \\
L T-\quad .17 \\
(.39)
\end{array}
$$




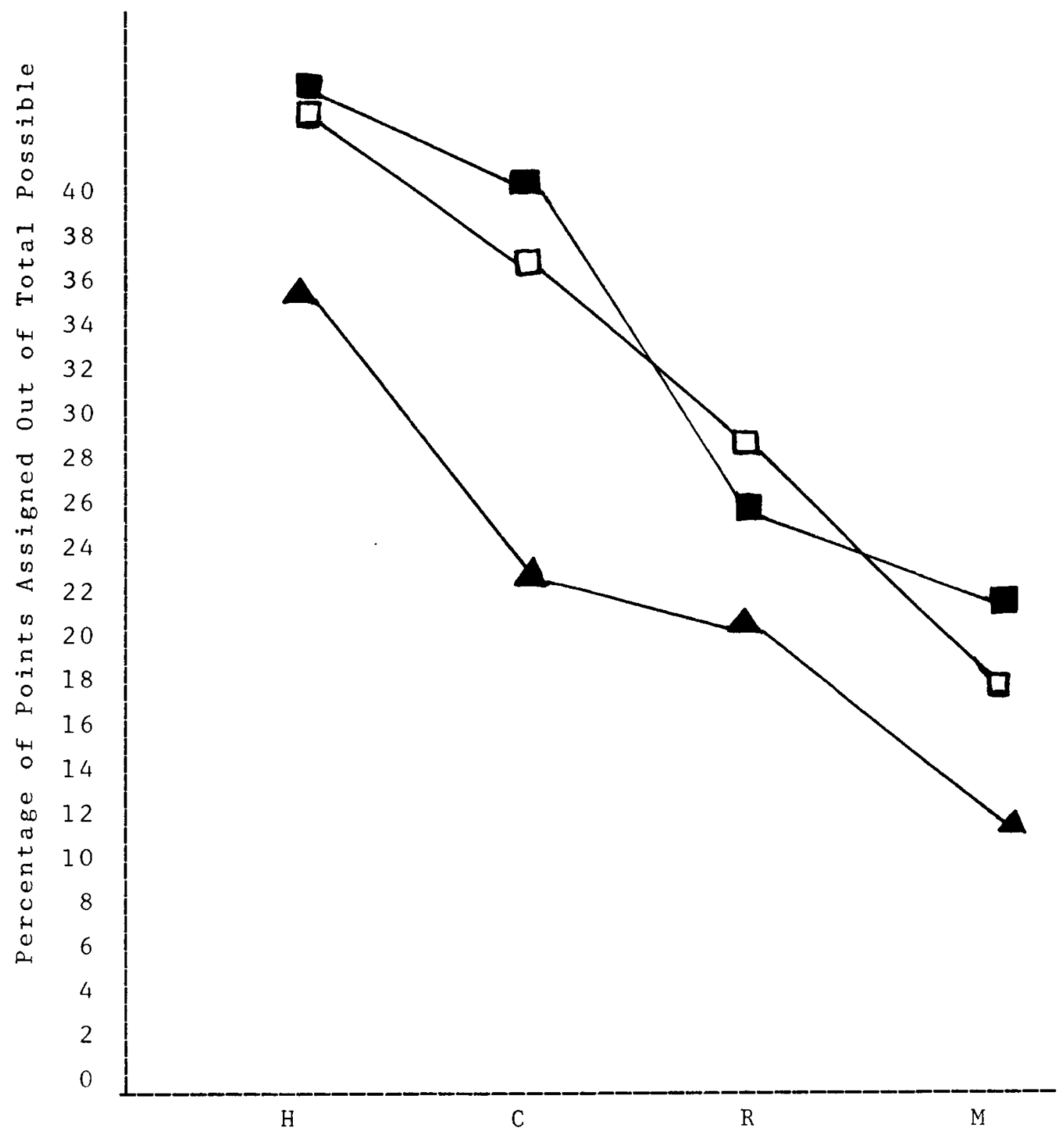

Figure 1. Order in which parents ranked their concerns about the behaviors displayed by their children on the CPS.

Key :

$\mathrm{H}=$ Hyperactivity, $\mathrm{C}=$ Conduct, $\mathrm{R}=$ Relationships, $\mathrm{M}=$ Mood

$\square=$ LD Subjects, $\boldsymbol{\square}=$ Late Talkers, $\boldsymbol{\Lambda}=$ Normal Subjects 
conduct while parents of the normal language children displayed the most concern for their child's health. However, parents of normal children did assign the second highest percentage of points possible to the area of conduct. The parents of the "late talkers" were also more concerned about their child's health than for any of the other behavioral 1tems, ranking it second highest. For the LD subjects parents considered hyperactivity/ADD (number 2) to be more of a concern than health (number 3 ). Parents of the normal language subjects ranked mood as their third area of concern. Mood was ranked fifth by parents of both the LD subjects and the "late talkers." Parents of all three subject groups considered relationships to be their fourth area of concern. Hyperactivity/ADD was ranked as fifth by parents of the normal language subjects. Stereotypical behaviors were listed as the area of least concern by parents of all three subject groups. The results are displayed in Figure 2

\section{SCUSSION}

The two questionnaires, the CPS and the BCT both show the LD subjects display significantly higher scores in the area of hyperactivity/ADD than the normal subjects. This finding is in agreement with the 1978 study of British children conducted by stevenson and Richman. They found that 3year old language delayed children display significantly 


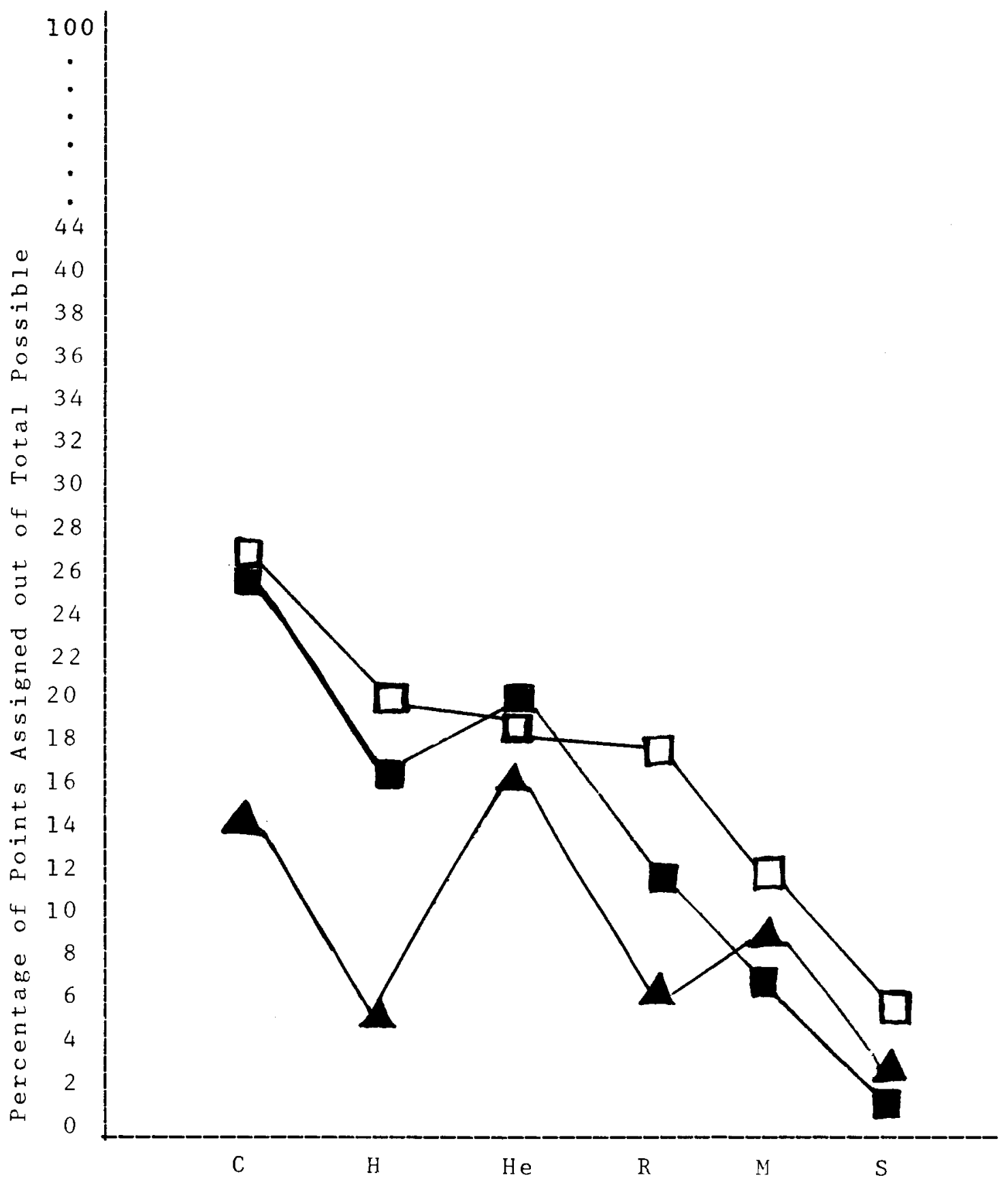

Figure 2. Order in which parents ranked their concerns about the behaviors displayed by their children on the BCT.

Key :

$\mathrm{H}=$ Hyperactivity/ADD, $\mathrm{R}=$ Relationships, $\mathrm{M}=$ Mood, $C=$ Conduct, $\mathrm{He}=$ Health, $\mathrm{S}=$ Stereotypical Behaviors $\square=$ LD Subjects, $\square=$ Late Talkers, $\boldsymbol{Q}=$ Normal Subjects 
higher scores in the areas of overactivity ( $p<.01$ ) and poor concentration $(\mathrm{p}<.01)$. Hyperactivity and attention deficit disorder have also been found to occur more frequently in subjects diagnosed as childhood aphasics (Paul, Cohen, \& Caparulo, 1983; Paul \& Cohen, 1984), and in schoolage children with less severe language delay (Wylie, et al., 1965; Botelho, 1986).

The two questionnaires also were in agreement that no significant differences exist between the normal subjects and the "late talkers" nor between the LD subjects and the "late talkers." This finding indicates that the scores of the "late talkers" fall midway between the scores of the normal language and $L D$ subjects in terms of their maladaptive behaviors.

There are two categories on which the two questionnaires differed; relationships and conduct for the normal and LD subjects. The CPS showed the LD subjects to have a significantly higher mean conduct score than the normal language subjects. Although the BCT showed the LD subjects to have more problems with conduct than the normal language subjects, the difference was not statistically significant.

Another area of difference is that the BCT showed the LD subjects to have a significantly higher mean for immature relationships than the normal language subjects. Again, while the CPS did not show a statistically significant difference between the normal and LD subject groups, the LD 
group did recelve a higher mean score. This researcher does not find it wholly unexpected that differences exist between the two questionna1res. In comparing the items on the CPS and the BCT, it can be seen that for several of the categories, the items on the two questionnaires are quite different, particularly in the areas of relationships and conduct. The conduct category on the CPS includes only two items, 1.e., "disturbs other children" and "temper out bursts." The BCT has four items that comprise the category of conduct, 1.e., "difficult to manage," "temper tantrums," "agression" and "defiant."

This researcher cannot say with certainty which of the questionnaires more accurately reflects the actual behavior of the subjects. However, there are at least three possible reasons for the differences. First, on the CPS there are only two items categorized as conduct. It may be that if the CPS contained more items in the category of conduct the difference between the normal and delayed language subjects may not have been significant. Also, the items on the BCT are more relevant for toddlers than the items on the CPS. The BCT may be a more accurate reflection of the behavior of the children in the study. However, the possibility exists that the CFS is actually a more sensitive measure of the parent's true opinion. It may be that since the CPS simply requires the parent to state how frequently the behavior occurs, the parent is responding more accurately. A parent 
might be reluctant to label an unacceptable behavior as a "major problem" as is the case if the parent assigns the full number of points (2) on the BCT.

The research literature seems to support the findings of the CPS, that 1s, that language delayed children do show significantly more problems with conduct than do children with normal language skills. This has been the case with older language delayed children. Stevenson and Richman (1978) found that 3-year old language delayed children are slgnificantly more "difficult to control" than normal language children $(p<.001)$. However, they found no differences between the two groups in the area of "tempers." Mattison et al. (1980) in their study of 99 children from a community speech and hearing clinic stated that the speech and language disordered children were rated severe by parents for such behaviors as tantrums, which supports the findings of the CPS in this study as "temper outbursts" was one of the two items labeled as conduct. Teachers rated this same group of children as having a problem with their attitude toward authority. Although the BCT did not find a statistically significant difference between the normal and ID subjects, it was filled out by parents only, not by teachers as was the case in the study conducted by Mattison et al. (1980). In comparing this study to that of Mattison et al. (1980) it must be remembered that the children in their study were in preschool or middle school. 
The relationships category on the BCT showed the LD subjects to score significantly higher than the normal language subjects. The CPS did not show a statistically significant difference between the two groups in this area, although the language delayed subjects did, on the average, score higher. For both questionnalres, five items comprise the category immature relationships. However, the items on the two questionnaires are quite different. The CPS relationship items are very specific and seem to portray a child who is unfriendly and does not enfoy receiving attention (See Appendix B for a complete listing of the items). The items on the BCT tend to show a child who, while not unfriendly is shy, overdependent, and has some problems getting along with his/her brothers and sisters. It may be that while problems with relationships do occur more frequently for children with delayed language, the manner in which the problems are manifested are more in terms of overdependence rather than withdrawal and hostility.

Other research tends to support the finding of the BCT for immature relationships (i.e. delayed language subjects show significantly more problems with relationships than do their normal language peers). Stevenson and Richman (1978) found that language delayed children displayed significantly higher scores in the areas of problems with dependency ( $p<$ .05), relationships with siblings ( $<.01$ ), and relationships with peers $(\mathrm{p}<.05)$. An interesting fact $1 \mathrm{~s}$ that 
Stevenson and Richman (1978) found no difference between the two groups in the area of attention seeking. Attention seeking was one of the 1tems on the BCT labeled as immature relationships. As a comparison of 1ndividual 1tems was not done in this study, 1 cannot be stated with certainty if this one item differed slgniflcantly between the two groups. Baker et al. (1980) also found older language delayed children to show signiflcantly more problems with relationships. Parents in that study named shy, fights with siblings, solitary and afraid of new people as being problem items for the combined speech and language 1 mpatred children.

No significant differences were found between e1ther the "late talkers" and the normal language subjects or between the "late talkers" and the LD subjects. It may be that if more "late talkers" had been included in the study more significant differences would have emerged.

The second cuestion addressed in this study was whether or not parents of the three subject groups differed in terms of what areas of behavior they were most concerned. It seems that parents of children in each group differ little on areas of most concern. No differences were found on the CPS and only minor differences were found on the BCT.

The only difference on the BCT between the "late talkers" and the LD subjects was that health and hyperactiv1ty/ADD were reversed for these two groups. Health was ranked second and hyperactivity/ADD third by the parents of 
the "late talkers." Parents of the LD subjects ranked their concern about their children' $\Xi$ hyperactivity/ADD second and concern about health third. Somewhat different results occurred for the normal subjects with parents' scoring revealing health to be their area of most concern. They placed hyperactivity/ADD quite low on their list of concerns (fifth). This $1 \leqslant$ not unexpected as one would expect parents of normal children to be more concerned about problems with eating and sleeping than anything else. Some difference in how parents ordered areas of concern may be due to the fact that health was not one of the categorles assessed on the CPS. These findings were supported by the research of Baker and Cantwell (1982b) who found that parents of language disordered children complained more frequently about hyperactivity and developmental problems while parents of pure speech disordered children complained more frequently about somatic complaints.

It is interesting to note though, that parents of normal language subjects ranked hyperactivity/ADD fifth on the BCT when they ranked it first on the CPS. This difference may in part be due to the fact that two of the three items on the BCT have to do with the child's ability to concentrate and his/her attention span, while on the CPS there are more items which assess the child's level of activity. It may be that parents of normal children are more concerned with excess energy than they are with short attention span. 
Hyperactivity/ADD also was ranked lower on the BCT than on the CPS by parents of both the "late talkers" and the LD subjects.

The finding from this research that little difference exists in the types of maladaptive behaviors displayed by language delayed and normal language children is supported by Cantwell and Baker (1977) and Stevenson and Richman (1978). It also has been found that the types of psychiatric disorders displayed by children with more severe handicaps (e.g. brain damage and intellectual retardation) do not differ markedly from the types of psychiatric disorders seen in the general population (Cantwell \& Baker, 1977). In other words, the same types of maladaptive behaviors are seen in both normal and language delayed children, but language delayed children display more maladaptive behaviors than non-language delayed children. 


\section{CHAPTER V}

\section{SUMMARY AND IMPLICATIONS}

\section{SUMMARY}

Human beings rely on language to share their thoughts and feelings, to express their needs and intentions. Without a shared language, man would be much the same as any other animal. It seems likely that if a children's language skills were impaired, it would have a negative impact on their social development. Several studies support the hypothesis that language delayed children are "at risk" for developing maladaptive behaviors (Cantwell \& Baker, 1977). To date there have been several studies which have looked at the behaviors of speech and/or language delayed children. However, only one of these studies focused primarily on preschool children. In 1978, Stevenson and Richman studied 3year old children in the London area to determine if language delayed children showed more maladaptive behaviors than nonlanguage delayed children. They found that even language delayed children as young as 3 years old have significantly more maladaptive behaviors than their nonlanguage delayed peers. However, it cannot be assumed from this study that even younger children will follow the same trend. Therefore, this study was designed to look at chil- 
dren in the earliest stages of language development. The subjects ranged in age from 18 to 41 months.

The questions addressed by this study were:

1) Is there a significant difference in the severity and frequency of maladaptive behaviors seen in language delayed children, non-language delayed children, and children who were "late talkers" between the ages of 18 and 41 months as reported by parents? and; 2) Is there a difference among the subject groups in terms of which behaviors parents are the most and least concerned about. The means and standard deviations were computed for each category of behavior reported on the two parent questionnalres. Differences were determined by comparing the results between the three groups of subjects using t-tests and were considered significant at the. 01 level.

The data was analyzed using t-tests because this researcher felt from looking at the raw data and from reviewing the literature that differences would exist among the three groups. The purpose of this study was to determine what those differences were. Differences were considered significant only at the. 01 level because of the large number of $t$-tests conducted. It was felt that using a lower level of significance would result in too high a chance of Type I errors.

In looking at the results of this study, it can be seen that even very young language delayed children and 
those who begin talking late are "at risk" for increased maladaptive behaviors. The language delayed children recelved significantly higher scores than the normal language children in the areas of hyperactivity (as reported both on the CPS and the BCT), conduct (CPS only) and relationships (BCT only).

\section{MPL I CAT IONS}

\section{Research Implications}

There are several interesting findings from this study, but the need for further research still exists. A limitation of this study is that only 11 to 12 subjects were used in the groups of "late talkers." It would be useful to conduct a study with a larger sample of "late talkers." Perhaps if more "late talkers" had been included in this study, some significant differences would have been found between the "late talkers" and the other two subject groups.

Another area of further research would be to conduct a longitudinal study to determine whether or not changes in maladaptive behaviors are observed in the "late talkers" or the LD subjects over time and/or as their language improves. As there have been no studies conducted to date as to what types of maladaptive behaviors are displayed by children who begin talking late, it would be especially useful to know whether or not their behavior improves over time or whether it remains the same. If these behaviors were to improve as 
the children's language improved it could then be hypothesized that the children's inability to express themselves clearly led to the maladaptive behaviors.

Since these maladaptive behaviors do manifest themselves so early, however, it seems likely that language is not a direct cause of the maladaptive behaviors but rather that both occur due to some other mutual cause, such as temperamental differences, inability to learn pro-social skills, inability to use models in the environment or interaction with parenting style. It may be that the temperaments of children with language disorders differ from those of children without language disorders. If differences exist in this area, it could affect how parents perceive their children, thereby influencing how they describe their behaviors. Also, a mismatch between the temperament of the chlld and the parent could influence the child's personality development. This factor was considered before beginning the study, but at the time, no measurements of temperament were avallable for children under 4 years of age.

Other researchers have hypothesized that both psychiatric disorders and speech and language disorders are due to some mutual cause. Cantwell and Baker (1977) hypothesized that both could be due to such common antecedents as intellectual retardation, deafness, or brain damage. These factors were taken into consideration in this study. All children who participated in the study had normal intelli- 
gence and normal hearing, and none of the children in the study had brain damage. It may be that only an indirect link exists between speech and language disorders and behavior disorders (Rutter, 1972). It is only through further research that these questions will be answered.

A further limitation of this study was that neither the CPS nor the BCT have been evaluated for reliability or validity. The results of this study would perhaps be strengthened if that Information were avallable.

\section{Clinical Implications}

This study has several important implications for the practicing speech-language pathologist. First, it provides support for the trend toward early intervention. Second, it provides some evidence that even children who begin talking late but then talk normally are still more likely to display more maladaptive behaviors than their normal language peers. Third, it points out the need for a multidisciplinary team approach to early childhood intervention. In looking at the findings from this research, it can be seen that even very young language delayed children are more likely than their normal peers to display inappropriate behaviors. In looking at the research to date, it can be hypothesized that since older language delayed children display significantly more maladaptive behaviors than their normal language peers that these behaviors are not going to just disappear. It is important that speech-language pathologists share with other 
professionals the knowledge that even very young language delayed children are more likely to develop maladaptive behaviors. As the same types of behaviors are observed in older language delayed children (Cantwell \& Baker, 1977) it does not seem that simply ignoring the problem makes it go away. This leads to the issue of whether or not speechlanguage pathologists should be concerned about the child who begins to talk late.

In the past, parents were often told not to worry if their children did not say their first word until two or ever three years of age. However, this study gives reason for some concern. Although no significant differences were found between the normal language children and the "late talkers," there was a definite trend for the "late talkers" to display higher scores in almost all areas assessed. This indlcates that while the "late talkers" do not have behavioral problems as severe as those of the LD children, they are still "at risk" and should not be considered "normal." If nothing else, it might be reassuring for parents of children who are "late talkers" to know that certain differences in behavior should not be totally unexpected for their child.

Finally, this study underscores the need for a multidisciplinary team approach in early language intervention. The speech-language pathologist must be prepared to see more maladaptive behaviors in language delayed children and must 
have knowledge of how to deal with those behaviors. Botelho (1986), in discussing the findings for her research, made the point that speech-language pathologists and psychologists must work together to find the best possible treatment plan for language delayed children. She wrote:

A team approach may be most effective in working with the child, as the speech-language pathologist can provide information to the school psychologist/counselor to help them understand the language component of the behavior problem and they can provide the speech-language pathologist with appropriate techniques to deal with the behavioral problems to minimize interference with learning. (p. 65)

In looking at the combination of behavioral problems and language disorders seen even in children less than 3-years old, the importance of a multidisciplinary approach cannot be overstressed. It is difficult to determine as of yet, whether or not language disorders lead to behavioral disorders or whether the relationship between the two is less direct. The best approach therefore seems to be one that would allow the speech-language pathologist and the psychologist to combine their unique areas of knowledge to provide the best possible intervention for these children. 
SELECTED BIBL IOGRAPHY

Achenbach, T.M., and Edelbrock, C. (1983). Manual for the Child Behavior Checklist and Revised Child Behavior Profile. U.S.A: Queen City Printers, Inc.

American Psychiatric Association Task Force on Nomenclature and Statistics (1980). Diagnostic and Statistical Manual of Mental Disorders, (DSM--III) $3 \overline{r d}$ ed. Washington, D.C.: American Psychiatric Association.

Baker, L., and Cantwell, D.P. (1987). Factors associated with the development of psychiatric illness in children with early speech/language problems. Journal of Autism

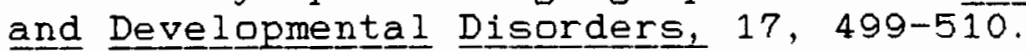

Baker, L., and Cantwell, D.P. (1982a). Developmental, social and behavioral characteristics of speech and language disordered children. Child Psychiatry and Human Development, $12,195-206$.

Baker, L., and Cantwell, D.P. (1982b). Psychiatric disorders in children with different types of communication disorders. Journal of Communication Disorgders, $15,113-136$.

Baker, I., CantwelI, D.P., and Mattison, R. E. (1980). Behavior problems in children with pure speech disorders and in children with combined speech and language disorders. Journal of Abnormal Chiㅛㅁㅡ Psychoㅣ믈, 8, 245-256.

Bayley, N. (1969). The Bayley Scales of Infant Development. At lanta: The Psychological Corporation.

Beckey, R.E. (1942). A study of certain factors related to retardation of speech. Journal of Speech Disorders, 7 , 223-249.

Botelho, J.S. (1986). A Comparison of Behavioral Problems Between Speech and /or Language Impaired Chilidren and Normal Children. Thesis submitted at Portland state University. 
Camarata, S.M., Hughes, C.A., and Ruhl, K.A. (1988). Mild/ moderate behaviorally disordered students: A population at risk for language disorders. Language, Speech and Hearing Services in the Schools, 19, 191-200.

Cantwel1, D.P., and Baker, L. (1980). Psychlatric and behavioral characteristics of children with communication disorders. Journal of Pediatric Psycholology, 2, 161-178.

Cantwel1, D.P., and Baker, L. (1977). Psychiatric disorder in children with speech and language retardation: Archives of General Psychlatry, 34, 583-591.

Cantwel1, D.P., Baker, L., and Mattison, R. E. (1979). The prevalence of psychiatric disorder in children with speech and language disorder: An epidemiological study. American Academy of Ch11d Psychlatry Journal, $18,450-\overline{461}$.

Chess, S., and Rosenberg, M. (1974). Clinical differentiation among children with initial language complaints. Journal of Aut1sm and Childhood Schizophrenia, $4,99-\overline{109}$.

Cohen, D. (1975). The Childhood Personality Scale. Washington, D.C.: The National Institute of Mental Health.

Conners, C.K. (1973). Rating scales for use in drug studies with children,. Psychopharmacology Bulletin, 24-59.

Hammil1, D., and Newcomer, P. (1982). Test of Language Development--Intermediate. Austin, TX: $\overline{\mathrm{P}} \overline{\mathrm{R} O} \overline{\mathrm{ED}}$.

Ingram, T.T.S. (1959). A description and classification of the common disorders of speech in children. Archives of Dis $\underline{1}$ order. 1 in Children, $36,444-467$.

Laughton, J., and Hasenstab, M.S. (1986). The Language Learning Process: Implications for Management of Disorders. Maryland: Aspen Publishers, Inc.

Mattison, R., Cantwel1, D.P., and Baker, L. (1980). Behavior problems in children with speech and language retardation. Child Psychiatry and Human Developoment, $10,246-257$.

Myers, J. K., and Bean, L. L. (1968). A Decade Later: A Follow-Up of Soclal Class and MentaI Illness. New York: Wiley \& Sons. 
Orton, S.T. (1937). Read1ng, Writ1ng, and Speech Problems in Children. New York: W. W. Norton Co., Inc.

Paul, R., and Cohen, D.J. (1984). Outcomes of severe disorders of language acquisition. Journal 으 Aut1sm and Devel oㅡmpental D1sorders, $14,405-421$.

Paul, R., Cohen, D.J., and Caparulo, B.K. (1983). A longitudinal study of patients with severe developmental disorders of language learning. Journal of the American Academy of Child Psychlatry, 22, 525534.

Rescorla, L. (In press). The language development survey: A screening tool for delayed language in toddlers.

Rescorla, I. (1984). The Behavior Checkl1st for Toddlers: Language Delay at Two. Paper presented at the National Conference of the American Academy of Child Psychiatry. Boston, MA.

Rutter, M. (1972). Psychiatric causes of language retardation, in M. Rutter (ed.) The Child with Delayed Speech. London: W1ll1am Heinemann, Ltd.

Rutter, M. , Graham, P., and Yule, W. (1970). A NeuroPsych1atric Study in Children. Suffolk, England: Lavenham Press, Ltd.

Spilka, B., and Steer, M.D. (1951). Incidence of speech and hearling deficiencies in the general population and schools of the U.S. Lafayette, IN: Purdue Speech and Hearing Clinic Staff.

Stevenson, J., and Richman, N. (1978). Behavior, language and development in three-year-old children. Journal 모 Aut1sm and Ch1 1 dhood Schizophrenia.

Van Riper, C. (1954). Speech Correction Principles and Methods. ( $3 r d$ edition). Englewood Cliffs: PrenticeHall, Inc.

Weiner, P.S. (1969). The emotionally disturbed child in the speech clinic: Some considerations. Journal of Speech and Hearing Disorders, 33, 158-167.

Wylie, H.L., Franchak, P., and McWilliams, B.J. (1965). Characteristics of children with speech disorders seen In a child guidance center. Perceptual Motor Skillis. $20,1101-1107$. 
APPENDIX A

LANGUAGE DEVELOPMENT SURVEY 
The Language Development Survey

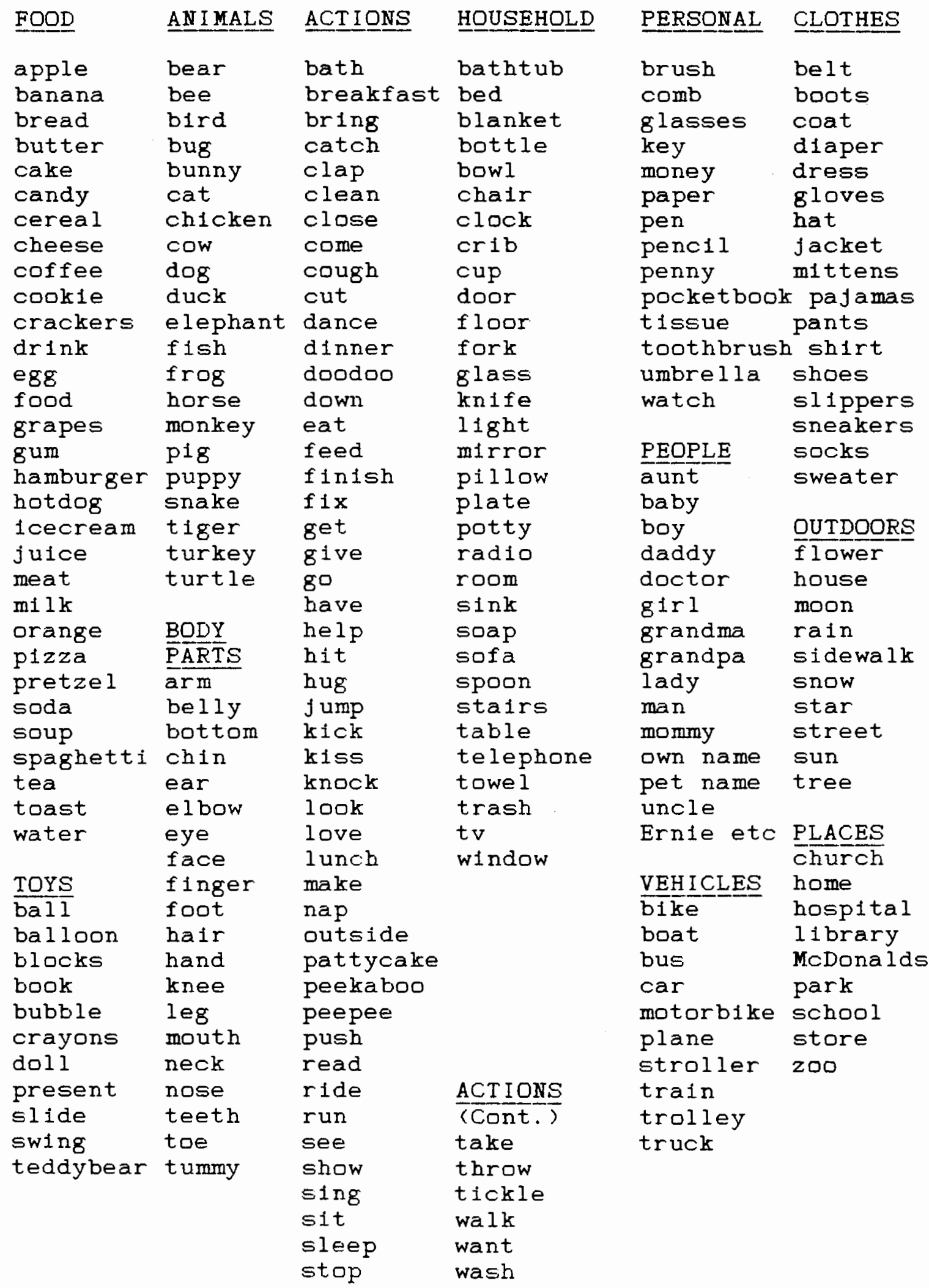


MODIFIERS

aligone

ali right

bad

big

black

blue

broken

clean

cold

dark

dirty

down

good

happy

heavy

hot

hungry

little

mine

more

open

pretty

red

shut

stinky

that

this

tired

up

wet

white

yellow

yucky

\section{OTHER}

$A, B, C$ etc

away

booboo

byebye

curse words

here

hi, hello

in

me

meow

my

myself

nightnight

no

of $f$

on

out

please

Sesame Street

scuse me

shut up

thank you

there

under

we l come

what

where

why

woof woof

yes

you

yumyum

$1,2,3$ etc
Please ilst any other words your child uses here:

Does your child combine two

or more words in phrases?

(e.g. more cookie, car

bye bye, etc)

yes __. no

Please list below THREE of

your child's longest and best sentences or phrases: 


\section{AFPENDIX B}

BEHAVIORAL ASSESSMENT QUESTIONNAIRES 


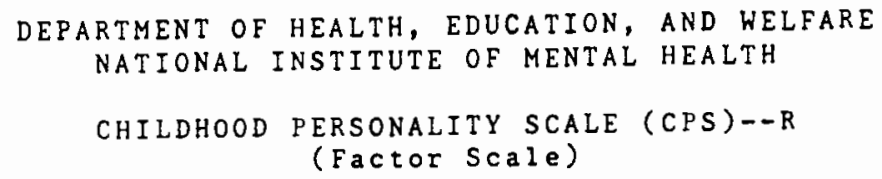

Father
- Mother

Family Name:

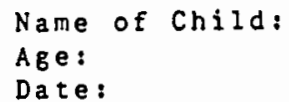

INSTRUCTIONS: The purpose of this questicrmaire is to get a picture of each child's personality as he or she typically has been for the last two months. Same of the senterces may describe the child very well. Other sentences will not be at all like this child. There are seven colums after each sentence. For each sentence, check the colulum that is most true of this child's perscnality and the way he acts.

This is an example of the type of question and how to answer it: Happy to sing when there are guests in the house.

\begin{tabular}{|c|c|c|c|c|c|c|}
\hline Never & $\begin{array}{l}\text { Almost } \\
\text { Never }\end{array}$ & Seldam & $\begin{array}{l}\text { Half } \\
\text { The } \\
\text { Time }\end{array}$ & $\begin{array}{c}\text { Fre- } \\
\text { quently }\end{array}$ & $\begin{array}{l}\text { Almost } \\
\text { Always }\end{array}$ & Always \\
\hline 0 & 1 & 2 & 3 & 4 & 5 & 6 \\
\hline
\end{tabular}

If this child always sings when there are guests, you should check colum " 6 ". If he never sings for company, check colum " $O$ ". If he sings sometimes but not always, check the box between " $O$ " and " 6 " that best describes him.

\begin{tabular}{|c|c|c|c|c|c|c|c|}
\hline & pever & $\begin{array}{l}\text { Almost } \\
\text { Never }\end{array}$ & seldam & $\begin{array}{l}\text { Half } \\
\text { The } \\
\text { Time }\end{array}$ & $\begin{array}{c}\text { Fre- } \\
\text { quently }\end{array}$ & $\begin{array}{l}\text { Almost } \\
\text { Always }\end{array}$ & Always \\
\hline & 0 & 1 & 2 & 3 & 4 & 5 & 6 \\
\hline \multicolumn{8}{|c|}{$\begin{array}{l}\text { H Loses interest in what he has started doing. Coes: } \\
\text { from one thing to another }\end{array}$} \\
\hline \multicolumn{8}{|c|}{$\begin{array}{l}\text { H rups, nus, and is on the move. Can't seem to } \\
\text { be still for long }\end{array}$} \\
\hline \multicolumn{8}{|l|}{$\begin{array}{l}R \text { Turns his head away or looks down in an uncam } \\
\text { fortable way when people pay attention to hir. }\end{array}$} \\
\hline \multicolumn{8}{|l|}{$\begin{array}{l}\text { M Lies down, rests his head, or fall asleep } \\
\text { instead of playing }\end{array}$} \\
\hline \multicolumn{8}{|c|}{$\begin{array}{l}\text { M Talks with delight. Cets pleasure out of almost } \\
\text { everything. }\end{array}$} \\
\hline \multicolumn{8}{|l|}{$\begin{array}{l}H \text { Persists in trying to do sonething, even if he } \\
\text { has same small problems along the way }\end{array}$} \\
\hline \multicolumn{8}{|l|}{$\begin{array}{l}\text { H Quickly shows his anger and fnustration if he } \\
\text { can't get something done that he's working on }\end{array}$} \\
\hline \multicolumn{8}{|l|}{$\begin{array}{l}\text { R Shies away from getting attention. Noves away } \\
\text { from people }\end{array}$} \\
\hline \multicolumn{8}{|c|}{$\begin{array}{l}\text { M Sits without doing anything unless another } \\
\text { person tries hard to get him interested }\end{array}$} \\
\hline \multicolumn{8}{|l|}{$\begin{array}{l}\text { Will talk or babble to you about his toys, } \\
\text { clothes, and what he is doing }\end{array}$} \\
\hline \multicolumn{8}{|l|}{$\begin{array}{l}\text { H Gives long attention to objects, toys, or } \\
\text { books that interest him. }\end{array}$} \\
\hline $\begin{array}{l}\text { H Can get away from you "quick as a flash" } \\
\text { hthen he bants to }\end{array}$ & & & & & & & \\
\hline
\end{tabular}




\begin{tabular}{|c|c|c|c|c|c|c|c|c|}
\hline & Never & $\begin{array}{l}\text { Almost } \\
\text { Never }\end{array}$ & Seldom & $\begin{array}{l}\text { Half } \\
\text { The } \\
\text { Time }\end{array}$ & $\begin{array}{c}\text { Fre- } \\
\text { quently }\end{array}$ & $\begin{array}{l}\text { Almast } \\
\text { Always }\end{array}$ & Always \\
\hline & & 0 & 1 & 2 & 3 & 4 & 5 & 6 \\
\hline $\mathrm{R}$ & Smiles to a friendly person & & & & & & & \\
\hline $\mathrm{M}$ & $\begin{array}{l}\text { segrs to have little zest for nomtal activi- } \\
\text { ties. Acts tired }\end{array}$ & & & & & & & \\
\hline$M$ & $\begin{array}{l}\text { Talks and acts happily and with excitement } \\
\text { about things that interest hin }\end{array}$ & & & & & & & \\
\hline $\mathrm{H}$ & $\begin{array}{l}\text { Can pay attention for a long time to sone- } \\
\text { thing }\end{array}$ & & & & & & & \\
\hline $\mathrm{H}$ & Active, inpossible to keep up with him & & & & & & & \\
\hline $\mathrm{R}$ & Tends to be resistant and unfriendly & & & & & & & \\
\hline$R$ & $\begin{array}{l}\text { Would rather be left alone if you try to } \\
\text { play with him or talk to him }\end{array}$ & & & & & & & \\
\hline & $\begin{array}{l}\text { Is a talkative child who expresses } \\
\text { himself in language or near language }\end{array}$ & & & & & & & \\
\hline
\end{tabular}

Listed below are itens about children's behavior or problens they sometimes have. How much do you think your child has been bothered by this problem at this time?

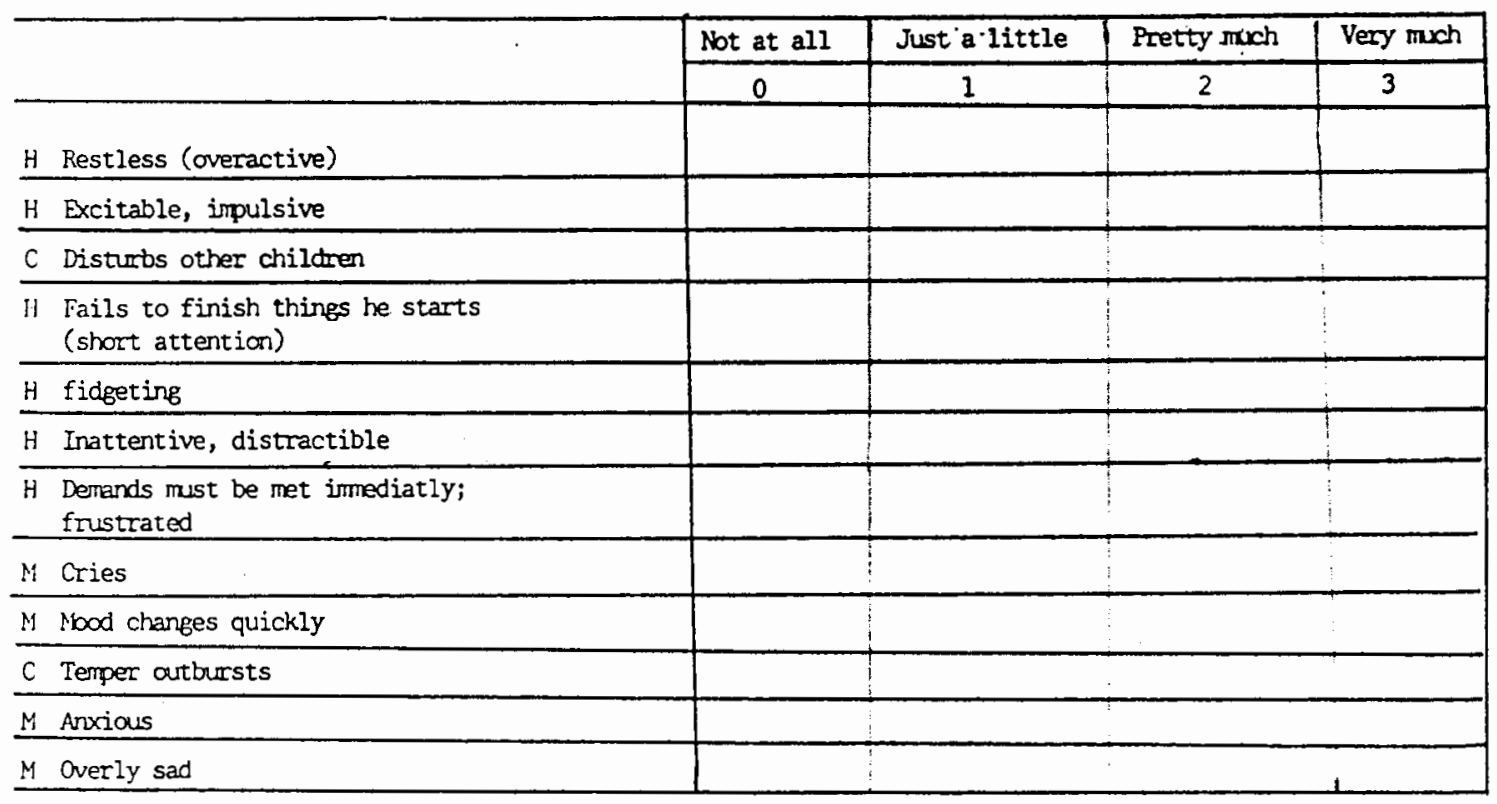

In comparison with other children his or her own age, how would you describe your child?

\begin{tabular}{|l|c|c|c|}
\hline & Better than most & Average & Slower than most \\
\hline langrage skills & $i$ & & 3 \\
\hline physical skills & & & \\
\hline social skills & & & \\
\hline emotional naturity & & & \\
\hline problem solving ability & & & \\
\hline
\end{tabular}


BEHAVIOR CHECKLIST FOR TODDLERS

CHILD' S NAME

PARENT'S NAME

DATE

He Eating

He Sleeping

$\mathrm{H}$ Overactivity

$\mathrm{H}$ Concentration

R Attention Seeking

$M$ Moods

$M$ Worries

$M$ Fears

C Difficult to Manage

C Temper Tantrums

C Agression

$R$ Shyness

M W1thorawn

$S$ Echoes speech

$S$ Repetitive habits (flapping, twirling)

$R$ Relationships with brothers/sisters

$\mathrm{R}$ Overly Dependent

$S$ Tics

Stutter $1 \mathrm{ng} /$ Stammering

$R$ Poor eye contact

M Cries or laughs too easily

$H$ Is impulsive

C Defiant

$S$ Peculiar Pre-

occupations

$S$ Rocks back and

forth

s Bangs head
NO

PROBLEM

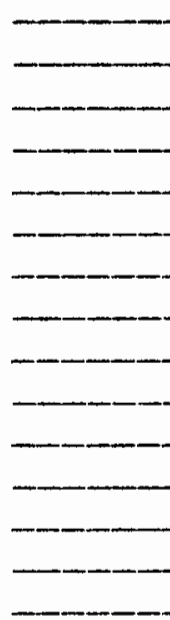

SOME

PROBLEM

MAJOR

PROBLEM
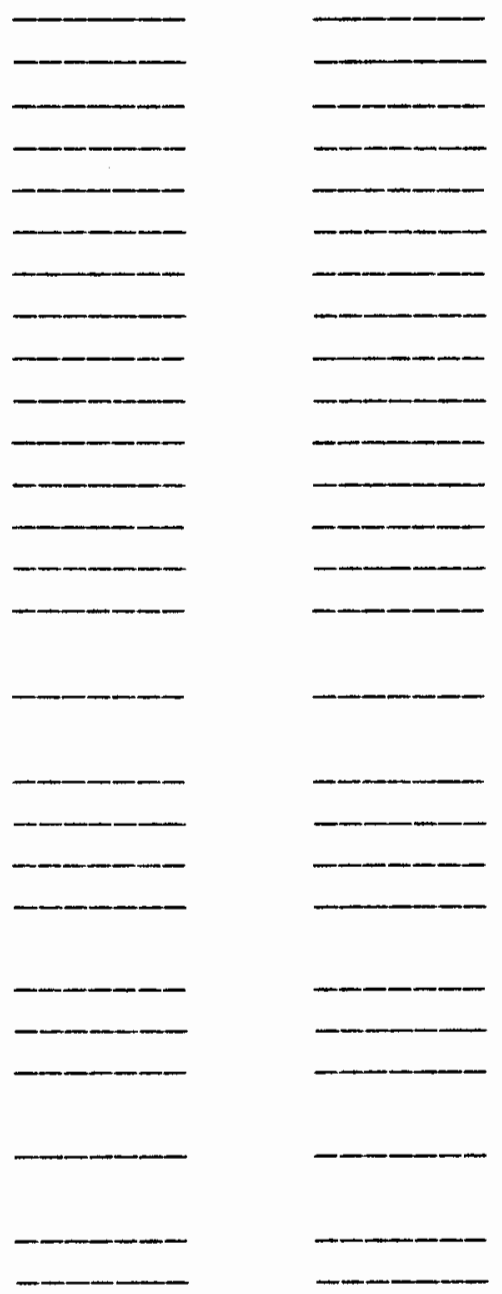

DOES YOUR CHILD HAVE PROBLEMS WHICH CONCERN YOU IN ANY OTHER AREAS OF BEHAVIOR OR DEVELOPMENT? 
AFPENDIX C

CODING FORMS 
CHILDHOOD PERSONALITY SCALE

SCORE FORM

NAME

CODER

AGE

DA T E

\begin{tabular}{|c|c|c|c|c|c|}
\hline \multicolumn{2}{|c|}{ HYPERACT IVITY } & \multicolumn{2}{|c|}{ MOOD } & \multicolumn{2}{|c|}{ RELATIONSHIPS } \\
\hline Question * & of Points & Question 非 & if of Points & Question : & of Points \\
\hline$H_{1}$ & & $M_{1}$ & & $\mathrm{R}_{1}$ & \\
\hline $\mathrm{H}_{2}$ & & $M_{2}$ & & $\mathrm{R}_{2}$ & \\
\hline $\mathrm{H}_{3} *$ & & $M_{3}$ & & $\mathrm{R}_{3}$ & \\
\hline $\mathrm{H}_{4}$ & & $M_{4} *$ & & $\mathrm{R}_{4}$ & \\
\hline $\mathrm{H}_{5}$ & & $M_{5}$ & & $\mathrm{R}_{5} *$ & \\
\hline $\mathrm{H}_{6}$ & & $M_{6}$ & & TOTAL & \\
\hline $\mathrm{H}_{7} *$ & & $\mathrm{M}_{7}$ & & & \\
\hline $\mathrm{H}_{8}$ & & $M_{8}$ & & & DUCT \\
\hline $\mathrm{H}_{9}$ & & $M_{9}$ & & Question \# & $\#$ of Points \\
\hline${ }^{\mathrm{H}} 10$ & & & & $\mathrm{C}_{1}$ & \\
\hline $\mathrm{H}_{11}$ & & & & $\mathrm{C}_{2}$ & \\
\hline $\mathrm{H}_{12}$ & & & & & \\
\hline $\mathrm{H}_{13}$ & & & & & \\
\hline $\mathrm{H}_{14}$ & & & & & \\
\hline TOTAL & & TOTAL & & TOTAL & \\
\hline
\end{tabular}

* Reverse Scoring 
BEHAVIOR CHECKLIST FOR TODDLERS

SCORE FORM

NANE

$A G E$
CODER

DATE

\begin{tabular}{|c|c|c|c|c|c|}
\hline \multicolumn{2}{|c|}{ HYPERACTIVITY } & \multicolumn{2}{|c|}{ RELATIONSHIPS } & \multicolumn{2}{|c|}{ MOOD } \\
\hline Question 非 & \#t of Points & Question 非 & 非 of Points & Question 非 & \#. of Points \\
\hline $\mathrm{H}_{1}$ & & $\mathrm{R}_{1}$ & & $M_{1}$ & \\
\hline $\mathrm{H}_{2}$ & & $\mathrm{R}_{2}$ & & $\mathrm{M}_{2}$ & \\
\hline $\mathrm{H}_{3}$ & & $\mathrm{R}_{3}$ & & $M_{3}$ & \\
\hline \multirow[t]{2}{*}{$\mathrm{H}_{4}$} & & $\mathrm{R}_{4}$ & & $M_{4}$ & \\
\hline & & $R_{5}$ & & M 5 & \\
\hline TOTAL & & TOTAL & & TOTAL & \\
\hline \multicolumn{2}{|c|}{$\begin{array}{c}\text { STEREOTYPICAL } \\
\text { BEHAVIORS }\end{array}$} & \multicolumn{2}{|c|}{ CONDLCT } & \multicolumn{2}{|c|}{ HEALTH } \\
\hline Question : & $i t$ of Points & Question :! & $*$ of Points & Question & of Points \\
\hline $\mathrm{S}_{1}$ & & $\mathrm{C}_{1}$ & & He 1 & \\
\hline $\mathrm{S}_{2}$ & & $\mathrm{C}_{2}$ & & He 2 & \\
\hline $\mathrm{S}_{3}$ & & $\mathrm{C}_{3}$ & & $\mathrm{He}$ & \\
\hline $\mathrm{S}_{4}$ & & $C_{4}$ & & & \\
\hline$S_{5}$ & 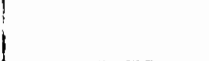 & & & & \\
\hline$S_{6}$ & & & & & \\
\hline TOTAL & & TOTAL & & TOTAL & \\
\hline
\end{tabular}


APPENDIX D

SUBJECT DATA 


\section{CHIILDHOOD PERSONALITY SCALEE}

NOERMAL

$\mathrm{H}$

$\begin{array}{rr}12 & 7 \\ 14 & 17 \\ 27 & 32 \\ 32 & 26 \\ 36 & 14 \\ 39 & 17 \\ 40 & 25\end{array}$

$50 \quad 28$

$55 \quad 11$

$56 \quad 30$

$58 \quad 29.5$

$59 \quad 22$

$63 \quad 26$

$72 \quad 37$

$78 \quad 14$

$81 \quad 33$

$113 \quad 29$

1269

$128 \quad 32$

$129 \quad 11$

$130 \quad 30$

$131 \quad 38$

$132 \quad 20$

1338

$138 \quad 34$

$139 \quad 21$

14120

14422

$150 \quad 36$

IOTAL 678.5

MEAN 23.40

S.D. $\quad 9.29$
$\mathrm{R}$

15

0

20

5

8

5

2
3

8

6

7

6

12

0

1

9

6

4

1

5

6

4

4

19

4

7

3
7

178

6.14

4. 71
M

C

20

$6 \quad 1$

2

111

$7 \quad 1$

5.52

31

11

10

62

$9.5 \quad 2.5$

$7 \quad 1$

61

14

10

4 1

63

$4 \quad 0$

$3 \quad 4$

21

3

42

4

42

3

$10 \quad 2$

81

51

$5 \quad 1$

147

39.5

$5.07 \quad 1.36$

$3.16 \quad .95$ 
BEHAVIOR CHECKLIST FOR TODDLERS

NORMAL

\begin{tabular}{|c|c|c|c|c|c|c|}
\hline & $\mathrm{H}$ & $R$ & M & $S$ & C & $\mathrm{He}$ \\
\hline 12 & 0 & 1 & 0 & 1 & 1 & 1 \\
\hline 14 & 0 & 0 & 0 & 0 & 0 & 1 \\
\hline 27 & 0 & 0 & 1 & 0 & 2 & 0 \\
\hline 32 & 1 & 2 & 1 & 0 & 3 & 2 \\
\hline 36 & 0 & 0 & 0 & 0 & 0 & 1 \\
\hline 39 & 0 & 0 & 0 & 1 & 2 & 0 \\
\hline 40 & 0 & 0 & 0 & 0 & 0 & 0 \\
\hline 41 & 0 & 0 & 0 & 0 & 0 & 0 \\
\hline 50 & 0 & 0 & 0 & 0 & 1 & 0 \\
\hline 55 & 0 & 0 & 0 & 0 & 0 & 0 \\
\hline 56 & 0 & 2 & 1 & 1 & 1 & 4 \\
\hline 58 & 0 & 0 & 3 & 0 & 3 & 0 \\
\hline 59 & 0 & 0 & 1 & 0 & 0 & 1 \\
\hline 63 & 1 & 1 & 2 & 1 & 1 & 0 \\
\hline 72 & 2 & 1 & 2 & 4 & 2 & 1 \\
\hline 78 & 0 & 0 & 0 & 0 & 2 & 1 \\
\hline 81 & 2 & 0 & 0 & 0 & 4 & 1 \\
\hline 113 & 0 & 0 & 1 & 0 & 0 & 0 \\
\hline 126 & 0 & 1 & 0 & 0 & 0 & 0 \\
\hline 128 & 0 & 1 & 0 & 0 & 2 & 0 \\
\hline 129 & 0 & 0 & 1 & 0 & 0 & 0 \\
\hline 130 & 0 & 0 & 0 & 0 & 0 & 0 \\
\hline 131 & 2 & 1 & 1 & 1 & 3 & 2 \\
\hline 132 & 0 & 2 & 0 & 0 & 2 & 0 \\
\hline 133 & 0 & 2.5 & 2 & 0 & 0 & 1 \\
\hline 138 & 0 & 1 & 0 & 0 & 1 & 2 \\
\hline 139 & 0 & 2 & 1 & 0 & 1 & 0 \\
\hline 141 & 0 & 0 & 0 & 0 & 1 & 0 \\
\hline 144 & 1 & 1 & 1 & 1 & 3 & 0 \\
\hline 150 & 0 & 0 & 2 & 0 & 0 & 1 \\
\hline TOTAL & 9 & 18.5 & 20 & 10 & 35 & 19 \\
\hline MEAN & .30 & .62 & .67 & .33 & 1.17 & .63 \\
\hline S. D. & .65 & .81 & .84 & .80 & 1.21 & .93 \\
\hline
\end{tabular}


CH I LDHOOD PERSONALITY SCALE

\section{DELAYED}

\begin{tabular}{|c|c|c|c|c|}
\hline & $\mathrm{H}$ & $\mathrm{R}$ & M & C \\
\hline 1 & 22 & 12 & 5 & 1 \\
\hline 6 & 55 & 14 & 23 & 3 \\
\hline 7 & 41 & 11 & 10 & 5 \\
\hline 15 & 23 & 6 & 10 & 1 \\
\hline 19 & 33 & 19 & 6 & 2 \\
\hline 29 & 39 & 4 & 13 & 3 \\
\hline 52 & 32 & 1 & 8 & 2 \\
\hline 53 & 25 & 1 & 2 & 0 \\
\hline 54 & 27 & 8 & 5 & 2 \\
\hline 57 & 28 & 18 & 13 & 1 \\
\hline 83 & 38 & 5 & 5 & 3 \\
\hline 85 & 24 & 9 & 8 & 3 \\
\hline 87 & 25 & 6 & 6 & 3 \\
\hline 88 & 30 & 8 & 3 & 0 \\
\hline 89 & 45 & 7 & 10 & 2 \\
\hline 90 & 29 & 13 & 5 & 2 \\
\hline 91 & 20 & 1 & 2 & 3 \\
\hline 92 & 11 & 13 & 2 & 1 \\
\hline 93 & 24 & 2 & 6.5 & 1 \\
\hline 94 & 28 & 18 & 1 & 2 \\
\hline 98 & 35 & 7 & 4 & 2 \\
\hline 102 & 43 & 4 & 8 & 1 \\
\hline 103 & 11 & 10 & 11 & 1 \\
\hline 105 & 37 & 7 & 4 & 2 \\
\hline 107 & 22 & 8 & 7 & 3 \\
\hline 111 & 33 & 21 & 9 & 6 \\
\hline 112 & 25 & 9 & 7 & 1 \\
\hline 114 & 31 & 16 & 12 & 2 \\
\hline 115 & 36 & 4 & 5 & 2 \\
\hline 116 & 40 & 1 & 3 & 5 \\
\hline 119 & 23.5 & 4 & 4 & 1 \\
\hline 142 & 32 & 2 & 15 & 4 \\
\hline 145 & 31 & 18 & 23 & 2 \\
\hline TOIAL & 998.5 & 287 & 255.5 & 74 \\
\hline MEAN & 30.26 & 8.70 & 7.74 & 2. \\
\hline S.D. & 9.23 & 5.88 & 5.30 & .38 \\
\hline
\end{tabular}




\section{BEHAVIOR CHECKLIST FOR TODDLERS}

DELAYED

$\begin{array}{lllllll} & \text { H } & \text { R } & \text { M } & \text { S } & \text { C } & \text { He } \\ 1 & 0 & 0 & 0 & 0 & 0 & 0 \\ 6 & 5 & 3 & 2 & 0 & 3 & 1 \\ 7 & 3 & 2 & 1 & 1 & 3 & 0 \\ 15 & 2 & 1 & 0 & 0 & 0 & 1 \\ 19 & 3 & 4 & 4 & 2 & 3 & 1 \\ 29 & 4 & 0 & 1 & 2 & 5 & 1 \\ 52 & 1 & 0 & 3 & 0 & 2 & 0 \\ 53 & 0 & 0 & 1 & 0 & 0 & 0 \\ 54 & 2 & 0 & 0 & 0 & 4 & 0 \\ 57 & 0 & 3 & 2 & 1 & 1 & 0 \\ 83 & 0 & 5 & 1 & 0 & 4 & 1 \\ 85 & 0 & 2 & 3 & 0 & 3 & 1 \\ 87 & 0 & 0 & 0 & 0 & 2 & 1 \\ 88 & 2 & 3 & 4 & 1 & 0 & 1 \\ 89 & 2 & 2 & 3 & 0 & 3 & 2 \\ 90 & 0 & 0 & 0 & 1 & 0 & 1 \\ 91 & 0 & 2 & 1 & 2 & 2 & 0 \\ 92 & 0 & 3 & 1 & 0 & 1 & 1 \\ 93 & 1 & 3.5 & 4 & 2 & 2 & 0 \\ 94 & 0 & 0 & 1 & 0 & 1 & 2 \\ 98 & 1 & 0 & 0 & 0 & 1 & 0 \\ 100 & 1 & 1 & 0 & 0 & 1 & 0 \\ 102 & 5 & 1 & 0 & 1 & 7 & 2 \\ 103 & 0 & 2 & 0 & 1 & 0 & 2 \\ 105 & 0 & 0 & 0 & 0 & 2 & 0 \\ 107 & 0 & 0 & 0 & 0 & 1 & 1 \\ 111 & 0 & 3 & 2 & 1 & 2 & 2 \\ 112 & 1 & 0 & 0 & 0 & 1 & 1 \\ 114 & 0 & 2 & 0 & 0 & 2 & 2 \\ 115 & 2 & 1 & 0 & 1 & 4 & 0 \\ 116 & 1 & 4 & 2 & 0 & 3 & 0 \\ 119 & 2 & 2.5 & 0 & 0 & 2.5 & 1 \\ 142 & 0 & 0 & 0 & 0 & 2 & 0 \\ 145 & 2 & 5 & 4 & 2 & 4 & 0 \\ \text { IOTAL } & 40 & 55 & 40 & 18 & 71.5 & 25 \\ \text { MEAN } & 1.18 & 1.62 & 1.18 & .53 & 2.10 & .74 \\ \text { S. D. } & 1.47 & 1.60 & 1.42 & .75 & 1.62 & .75\end{array}$




\section{CHI ILDHOOD PERSONALITY SCALE}

\section{LATEE IALLKEERS}

\begin{tabular}{|c|c|c|c|c|}
\hline & $\mathrm{H}$ & $\mathrm{R}$ & $M$ & c \\
\hline 4 & 37 & 13 & 13 & 3 \\
\hline 9 & 23 & 3 & 2 & 2 \\
\hline 26 & 35 & 15.5 & 9.5 & 1 \\
\hline 51 & 26 & 2 & 4 & 4 \\
\hline 86 & 27 & 5 & 6 & 2 \\
\hline 95 & 39 & 3 & 10 & 3.5 \\
\hline 97 & 25 & 7 & 4 & 2 \\
\hline 101 & 34 & 10 & 12 & 1 \\
\hline 109 & 45 & 8 & 20 & 5 \\
\hline 122 & 30 & 7 & 13 & 3 \\
\hline 184 & 21 & 11.5 & 11 & 1 \\
\hline TOIOIAL & 342 & 85 & 104.50 & 27.50 \\
\hline MEEAN & 31.09 & 7.73 & 9.50 & 2.50 \\
\hline S.. D. & 7.50 & 4.40 & 5.22 & 1.32 \\
\hline
\end{tabular}

\section{BEHAVIOR CHECKLIST FOR TODDLERS}

\section{LATE TALKEERS}

$\begin{array}{lllllll} & \mathrm{H} & \mathrm{R} & \mathrm{M} & \mathrm{S} & \mathrm{C} & \mathrm{He} \\ 4 & 2 & 2 & 0 & 0 & 6 & 2 \\ 9 & 1 & 0 & 0 & 0 & 0 & 2 \\ 26 & 2 & 2 & 1 & 1 & 0 & 0 \\ 51 & 0 & 0 & 0 & 0 & 0 & 0 \\ 60 & 0 & 2 & 0 & 0 & 2 & 1 \\ 86 & 0 & 0 & 0 & 0 & 0 & 0 \\ 95 & 2 & 2 & 0 & 0 & 4 & 1 \\ 97 & 0 & 0 & 0 & 1 & 2 & 1 \\ 101 & 2 & 1 & 0 & 0 & 3 & 0 \\ 109 & 1 & 3 & 4 & 0 & 7 & 1 \\ 122 & 1 & 1 & 1 & 0 & 2 & 1 \\ 184 & 0 & 1 & 1 & 0 & 1 & 9 \\ \text { TOTAL } & 11 & 14 & 7 & 2 & 25 & .75 \\ \text { MEAN } & .92 & 1.17 & .58 & .17 & 2.08 & \\ \text { S.D. } & .90 & 1.03 & 1.17 & .39 & 2.38 & .75\end{array}$


KEY:

H-Hyperactivity/Attention Deficit Disorder $\mathrm{R}-$ Relationships

M-Mood

C-Conduct

S-Stereotypical Behaviors

He-Health 